\title{
The Fungal Cell-Wall Integrity MAPK Cascade Is Crucial for Hyphal Network Formation and Maintenance of Restrictive Growth of Epichloë festucae in Symbiosis With Lolium perenne
}

\author{
Yvonne Becker, ${ }^{1}$ Carla J. Eaton,, ${ }^{1,2}$ Emma Brasell,, ${ }^{1}$ Kimberley J. May, ${ }^{1}$ Matthias Becker, ${ }^{1}$ Berit Hassing, ${ }^{1}$ \\ Gemma M. Cartwright, ${ }^{1}$ Leonie Reinhold, ${ }^{1}$ and Barry Scott ${ }^{1,2}$ \\ ${ }^{1}$ Institute of Fundamental Sciences and ${ }^{2}$ Bioprotection Research Centre, Massey University, Private Bag 11222 , \\ Palmerston North 4442, New Zealand
}

Submitted 26 June 2014. Accepted 28 September 2014.

Epichlö̈ festucae is a mutualistic symbiont that systemically colonizes the intercellular spaces of Lolium perenne leaves to form a highly structured and interconnected hyphal network. In an Agrobacterium tumefaciens T-DNA forward genetic screen, we identified a mutant TM1066 that had a severe host interaction phenotype, causing stunting and premature senescence of the host. Molecular analysis revealed that the mutation responsible for this phenotype was in the cell-wall integrity (CWI) mitogen-activated protein kinase kinase (MAPKK), $m k k A$. Mutants generated by targeted deletion of the $m k k A$ or the downstream $m p k A$ kinase recapitulated the phenotypes observed for TM1066. Both mutants were defective in hyphal cell-cell fusion, formed intrahyphal hyphae, had enhanced conidiation, and showed microcyclic conidiation. Transmission electron microscopy and confocal microscopy analysis of leaf tissue showed that mutant hyphae were more abundant than the wild type in the intercellular spaces and colonized the vascular bundles. Hyphal branches failed to fuse but, instead, grew past one another to form bundles of convoluted hyphae. Mutant hyphae showed increased fluorescence with AF488-WGA, indicative of increased accessibility of chitin, a hypothesis supported by changes in the cell-wall ultrastructure. These results show that the CWI MAPK pathway is a key signaling pathway for controlling the mutualistic symbiotic interaction between $E$. festucae and L. perenne.

The endophytic fungus Epichloe festucae is a mutualistic symbiont of Festuca and Lolium cool-season grasses (Christensen et al. 2002; Leuchtmann et al. 1994; Schardl 2001; Scott et al. 2012). This biotrophic fungus systemically colonizes the intercellular spaces of both vegetative and reproductive aerial tissues of the plant to form a highly structured and interconnected symbiotic hyphal network (Takemoto et al. 2006; Tanaka et al. 2006). Hyphae grow within the true stem of the grass by hyphal tip growth, from where they ramify into

Corresponding author: B. Scott; Telephone: (+64) 6-350 5168; Fax: (+64) 6-350 5688; E-mail: d.b.scott@ massey.ac.nz

* The $\boldsymbol{e}$-Xtra logo stands for "electronic extra" and indicates that seven supplementary figures and three supplementary tables are published online.

(C) 2015 The American Phytopathological Society leaf primordia and axillary buds that give rise to new leaves and new shoots, respectively. Within each leaf primordium, there are two zones of cell division, one that gives rise to the blade and the other to the sheath. Intercalary division of plant cells in both zones combined with leaf expansion results in stretching of hyphae. Remarkably, hyphae within these leaf expansion zones grow by intercalary extension; a pattern of growth that allows synchronization of hyphal growth with that of the rapidly expanding leaf (Christensen et al. 2008). Given that hyphae are firmly attached to the cell walls, this form of growth prevents mechanical shear of the hyphae as the leaves expand. Once leaf expansion ceases, growth of the hyphae also ceases, suggesting that signaling from the host controls fungal growth (Tan et al. 2001).

Establishment and maintenance of this symbiotic network of E. festucae within its host is dependent on a number of important fungal signaling pathways, including reactive oxygen species signaling from the NADPH oxidase (Nox) complex and signaling through the stress-activated mitogen-activated protein kinase (MAPK) pathway (Eaton et al. 2010; Tanaka et al. 2006). Disruption of noxA and fungal genes that encode additional components of this complex, including noxR, racA, and bem $A$, leads to a breakdown in the symbiosis; mutant hyphae switch from a pattern of restrictive to proliferative growth resulting in premature senescence and, frequently, death of the host (Takemoto et al. 2006, 2011; Tanaka et al. 2006, 2008). The demonstration that Neurospora crassa homologues of noxA (nox-1) and noxR (nor-1) were required for fusion of conidial anastomosis tubes (CATs) (Read et al. 2012) led us to propose that a lack of hyphal cell fusion in planta was responsible for disruption of the E. festucae symbiotic hyphal network in leaves of Lolium perenne. In support of this hypothesis, we showed that noxA, noxR, racA, and, to a lesser extent, bemA mutants were defective in cell-cell fusion when grown on water agar in axenic culture (Kayano et al. 2013). In addition, the noxA mutant was found to hyperconidiate, suggesting that the NoxA complex represses conidiation in E. festucae.

Disruption of proA, encoding a C6 zinc finger transcription factor, also led to a breakdown in the mutualistic symbiotic interaction between $E$. festucae and $L$. perenne (Tanaka et al. 2013). Homologues of this gene in Sordaria macrospora, $N$. crassa, and Aspergillus nidulans are required for sexual fruiting body development (Colot et al. 2006; Masloff et al. 1999; Vienken and Fischer 2006) and are defective in cell-cell fusion (Fu et al. 2011; Masloff et al. 2002). Like $\Delta$ noxA, the E. festucae 
proA mutant was also defective in hyphal cell fusion in axenic culture and had a hyperconidiation phenotype (Tanaka et al. 2013). Deletion of the E. festucae soft (so) gene, encoding a protein of unknown function required for chemotropic signaling during CAT fusion in $N$. crassa (Fleissner et al. 2009), also led to a hyphal cell fusion defect in culture and a severe symbiotic interaction phenotype (Charlton et al. 2012).

In the course of an Agrobacterium tumefaciens T-DNA mutagenesis screen for mutations that regulate the expression of indole-diterpene alkaloid biosynthetic genes (Young et al. 2005; Young et al. 2006), we isolated TM1066, a mutant that induced a host interaction phenotype very similar to that observed for the $\triangle$ noxA, $\Delta$ noxR, $\triangle$ racA, $\triangle p r o A$, and $\Delta$ so mutants. Here, we report that the gene responsible for this symbiosis phenotype, $m k k A$, encodes the cell-wall integrity (CWI) MAPKK.

\section{RESULTS}

\section{T-DNA induced mutant TM1066 is defective in cell fusion and symbiosis.}

To identify E. festucae genes that regulate the in-planta-specific expression of lolitrem (ltm) biosynthetic genes, a forward genetics screen was carried out using A. tumefaciens T-DNAmediated mutagenesis (Tanaka et al. 2007) of a PltmM-gusA "knock-in", strain KM2.49 (Supplementary Fig. S1A), to identify mutants that were either $\beta$-glucuronidase (GUS) positive in culture or GUS negative in planta. From approximately 1,400 T-DNA mutants screened, no mutants were obtained that were GUS negative in L. perenne seedlings. However, strain TM1066 induced severe stunting of the L. perenne host (Fig. 1A), a phenotype similar to that previously observed for plants infected with mutants in the Nox complex, including $\Delta$ noxA (Tanaka et al. 2006), $\Delta$ noxR (Takemoto et al. 2006), and $\Delta r a c A$ (Tanaka et al. 2008); a stress-activated MAPK mutant $\Delta s a k A$ (Eaton et al. 2010); and the $\mathrm{Zn}(\mathrm{II})_{2} \mathrm{Cys}_{6}$ transcription factor mutant $\Delta$ proA (Tanaka et al. 2013). Plants infected with TM1066 showed varying degrees of stunting, drastically reduced infection rates (6 to $18 \%$ ) compared with wild-type- or KM2.49-infected plants (75 to $85 \%$ ), and decreased seedling survival rates $(33 \%)$. Transmission electron microscopy (TEM) analysis of hyphae in the intercellular space of leaf sheath cross sections showed that mutant hyphae were more abundant than wild-type hyphae, readily colonized the plant vascular bundles, and formed intrahyphal hyphae (Fig. 1B). In wild-type associations, hyphae are generally excluded from vascular bundles, intercellular spaces are mostly colonized by one or two hyphae, and intrahyphal hypha are not formed (Christensen et al. 2008; Scott et al. 2012; Tanaka et al. 2006).

In axenic culture, the radial growth of TM1066 was slightly reduced compared with KM2.49 and the wild type (Fig. 1C). Both KM2.49 and TM1066 have an altered colony morphology compared with the wild-type strain, characterized by an increase in surface hydrophobicity and reduced formation of aerial hyphae. The fact that KM2.49 also has this phenotype suggests that this morphological change arose from generation of the PltmM-gusA knock-in. Light microscopy analysis showed that TM1066 is defective in cell-cell fusion and forms intrahyphal hyphae in culture (Fig. 1D), a phenotype indicative of a septum defect (Liu et al. 2008). A closer examination of the cell-cell fusion process occurring in the wild type revealed that $E$. festucae undergoes apical tip fusion (anastomosis) with an adjacent subapical cell (Fig. 2A). As the tip of the growing hypha extends, further cell-cell fusions occur with subapical compartments of the adjacent hypha to build a ladder-like structure connecting the two hyphae (Fig. 2C). Imaging of an Fl1 strain expressing mRFP1, growing alongside an Fl1 strain expressing enhanced green fluorescent protein (eGFP), demonstrated that, following cell-cell fusion, there is cytoplasmic migration and mixing between the two fused hyphae (Fig. 2B). The monomeric red fluorescent protein (mRFP1)-expressing hypha (top) appears to have undergone fusion with the subapical cell of an eGFP (green)-expressing hypha (bottom), followed by further growth of the hyphal tip and mixing of the cytoplasmic contents of the two hyphae. The merge of the mRFP1 and eGFP channels shows the progression of the cytoplasmic mixing.

Conidiation of E. festucae wild-type Fl1 on potato dextrose agar (PDA) is sparse but, when grown under nutrient-limiting conditions such as on water agar, a few conidia are produced predominantly from conidiophores that arise as lateral branches from coil-like hyphal structures (Kayano et al. 2013; Scott et al. 2012). TM1066 showed an increase in conidiation compared with the wild type and KM2.49 when grown on either water agar (Fig. 1D) or PDA (Fig. 3).

\section{Molecular analysis of the T-DNA integration event in TM1066 and complementation.}

Southern analysis of genomic digests of TM1066 probed with $\left[{ }^{32} \mathrm{P}\right]$-labeled pBSYT7 revealed the presence of a singlecopy T-DNA insertion. The sequence flanking the left border of the T-DNA was isolated by thermal asymmetrical interlaced polymerase chain reaction (TAIL-PCR). Subsequent PCR, sequence, and Southern blot analyses revealed that TM1066 contained a 2,221-bp deletion of the T-DNA, including the right border, and a 1,081-bp deletion of the E. festucae genome that included 3' coding sequences of pusA (EfM3.016600), encoding a pseudouridine synthase, and $m k k A$, encoding a CWI MAPKK.

The E. festucae pusA coding sequence is predicted to encode a polypeptide of 755 amino acids that shares $56 \%$ sequence identity with a Fusarium graminearum hypothetical protein, $31 \%$ with $N$. crassa pseudouridine synthase TruD/Pus7, and $31 \%$ with Magnaporthe oryzae tRNA pseudouridine synthase D (Supplementary Fig. S2). Pseudouridine synthases catalyze the isomerization of uridine to pseudouridine in a variety of RNA molecules, and may function as RNA chaperones (Ramamurthy et al. 1999). E. festucae PusA shows highest homology to the TruD family of pseudouridine synthases that modify uracil-13 in tRNA (Chan and Huang 2009).

The E. festucae mkkA coding sequence is predicted to encode a polypeptide of 532 amino acids that shares $82 \%$ sequence identity with $F$. graminearum Fgmkk2 (Fgmkk1), 68\% with $N$. crassa MEK-1, and $76 \%$ with $M$. oryzae Mkk1 (Supplementary Fig. S3). The MkkA/Mek1 protein is a central component of the CWI MAPK signal transduction pathway, where it acts as the kinase kinase phosphorylating the MpkA MAPK. The MkkA protein kinase domain is located between amino acids 235 and 505. Saccharomyces cerevisiae has two functionally redundant MEK (Mkk1/2) but filamentous fungi have just one copy (Irie et al. 1993). A tBLASTn analysis of the E. festucae genome using $N$. crassa Mak1 as the query sequence identified a putative homologue of the CWI MAPK downstream of MkkA, which we have called MpkA (EfM3.074990). The E. festucae mpkA coding sequence is predicted to encode a polypeptide of 418 amino acids that shares $92 \%$ sequence identity with $F$. graminearum Mgv1, 86\% with $N$. crassa Mak1, and $88 \%$ with $M$. oryzae Mps1 (Supplementary Fig. S4).

To determine which of the two genes deleted in TM1066 was responsible for the culture and symbiosis phenotypes, the $m k k A$ and pusA genes, under the control of their native promoters and terminators, were separately introduced into the genome of TM1066. Reintroduction of pYR31, containing 
$m k k A$, rescued the culture fusion and plant symbiotic interaction defects but not pYR29, containing pusA (Fig. 4).

The CWI MAPK pathway is essential for vegetative hyphal fusion and regulates conidiation.

Because TM1066 was not derived directly from the wild type and KM2.49 had a different culture morphology from the wild type, we made a targeted deletion of $m k k A$ and of the downstream MAPK $m p k A$ to confirm that a functional CWI MAPK pathway is essential for hyphal fusion, regulation of conidiation, and symbiosis. Linear fragments of pCE63 and pCE64 containing replacement cassettes for $m k k A$ and $m p k A$, respectively, were generated by PCR and transformed into protoplasts of Fl1. PCR screening of 72 arbitrarily chosen hygromycin-
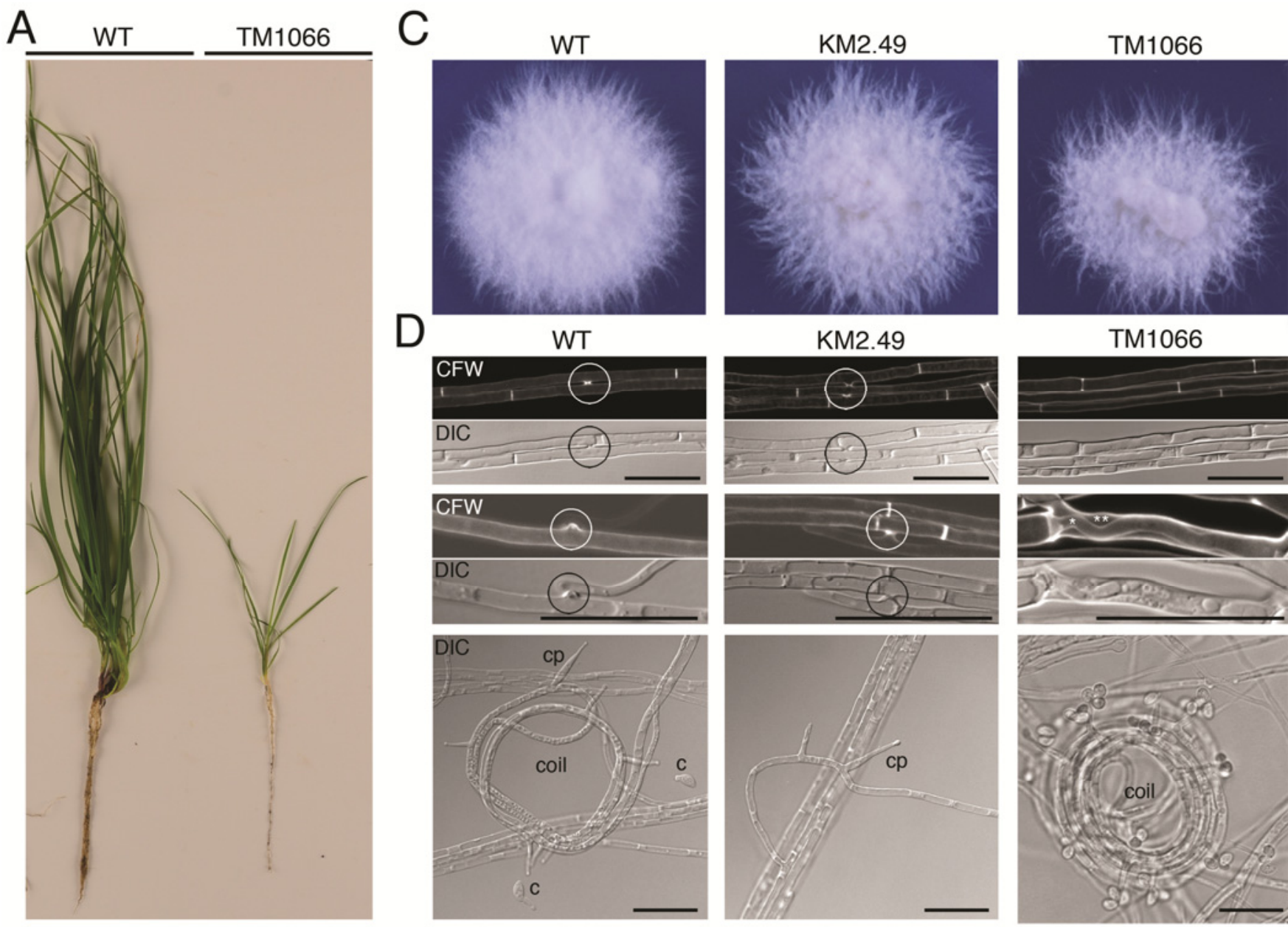

B
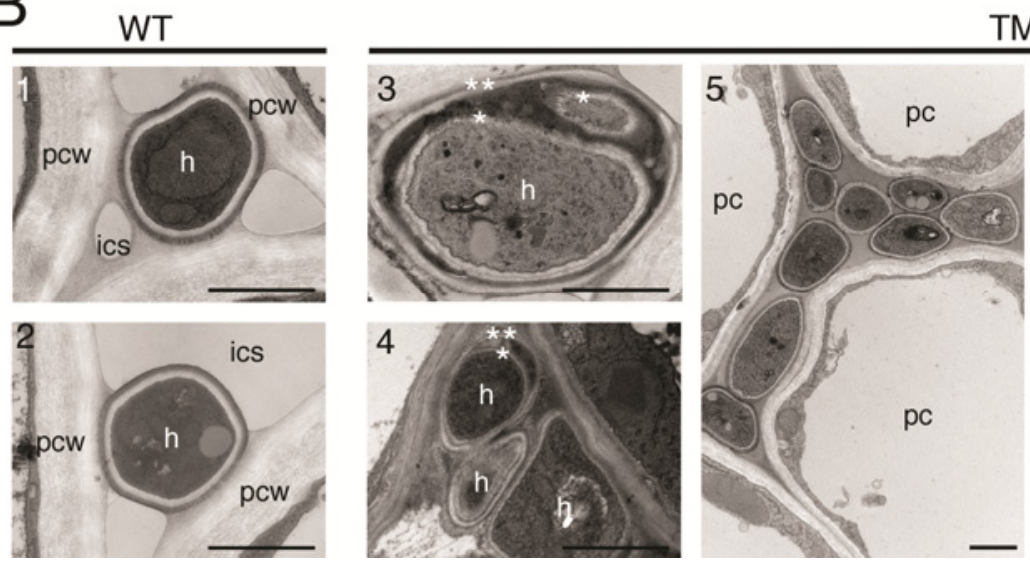

TM1066

Fig. 1. TM1066 mutant phenotype. A, Phenotype of perennial ryegrass plants infected with Epichloë festucae wild-type (WT) strain Fl1 and T-DNA mutant TM1066. Photograph was taken 9 weeks postinoculation. B, Transmission electron micrographs of cross-sections of E. festucae WT and mutant TM1066 growing in Lolium perenne. Hyphae colonizing a plant vascular bundle are circled in box 6. Pseudostem cross sections were made 9 weeks postinoculation. Symbols: $*=$ inner hypha, ${ }^{*}=$ outer hypha, $\mathrm{h}=$ hypha, $\mathrm{pc}=$ plant cell, $\mathrm{pcw}=$ plant cell wall, ics $=$ intercellular space. Bars $=1 \mu \mathrm{m}$ in boxes 1 to 5 and $10 \mu \mathrm{m}$ in box 6. C, Culture phenotype of E. festucae WT strain Fl1, PltmM-gusA knock-in strain KM2.49, and T-DNA mutant TM1066 grown on potato dextrose agar for 6 days. D, Confocal laser-scanning and differential interference contrast microscopy images of hyphal morphology of $E$. festucae hyphae grown on water agar $(1.5 \%)$ for 6 days. Cultures were stained with Calcofluor white (CFW). Hyphal anastomoses in WT and KM2.49 are circled. Symbols: $\mathrm{c}=$ conidium, $\mathrm{cp}=$ conidiophore, $*=$ inner hypha, $* *=$ outer hypha. Bars $=20 \mu \mathrm{m}$. 
resistant transformants from each transformation with primer sets mkk5/6 and mpk5/6 identified 10 and 13 putative replacements, respectively. Additional PCR screening with primer sets that amplify the left and right flanks of the insertion ( $m k k A$ : mkk3/TC45 and mkk4/TC44; mpkA: mpk3/TC45 and mpk4/
TC44) identified five (numbers 2-4, 3-9, 4-2, 4-7, and 8-3) putative replacements of $m k k A$ and seven (numbers 7-4, 8-3, 8-5, 10-8, 12-6 13-6, and 13-7) of mpkA (Supplementary Fig. S5). Southern blot analysis of genomic digests of these transformants confirmed that all were true replacements; four of the
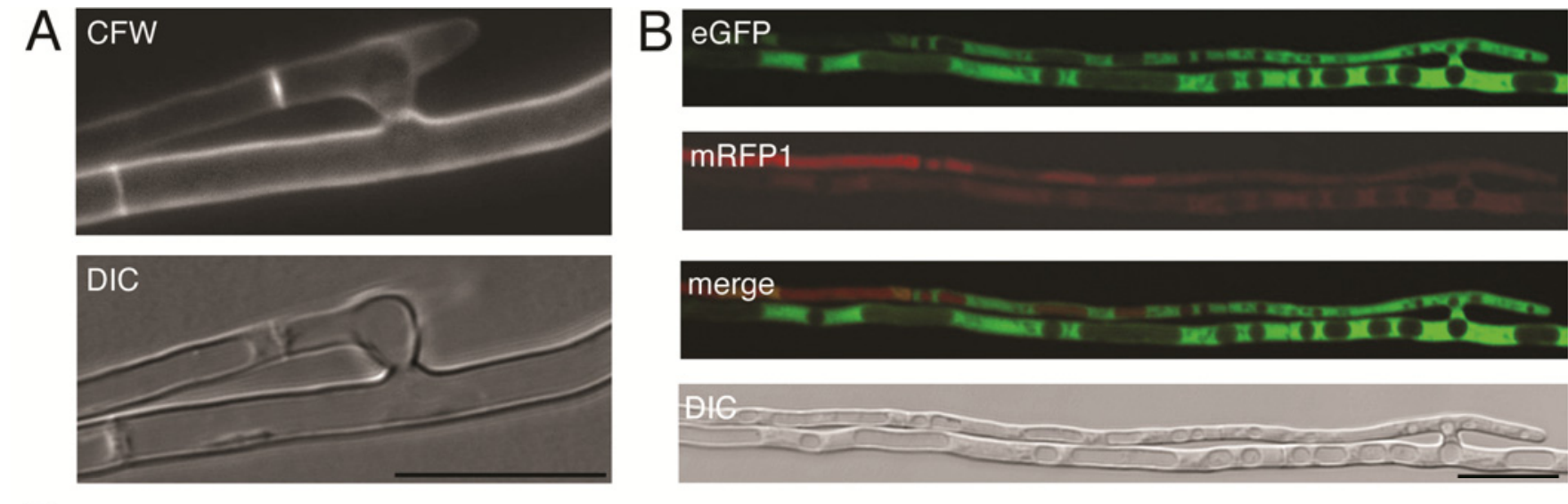

$\mathrm{C}$

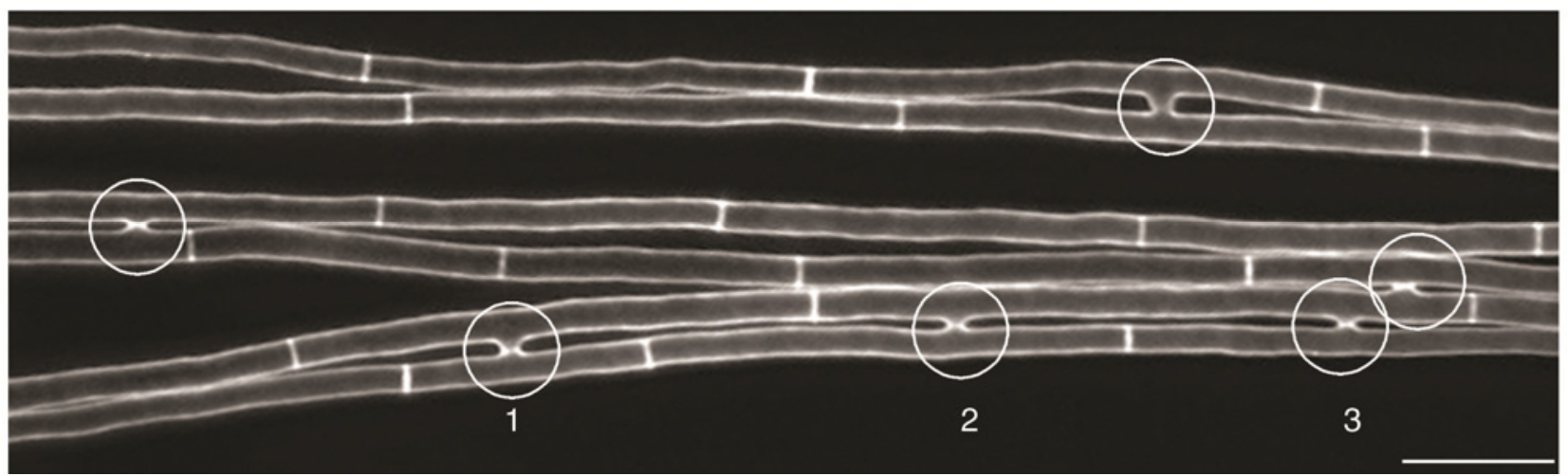

Fig. 2. Confocal laser-scanning and differential interference contrast (DIC) microscopy images of hyphal fusion in Epichloë festucae wild-type cultures grown on water agar for 6 days. Cultures were stained with Calcofluor white (CFW) in A and C. A, Hyphal tip fusion with adjacent subapical cell compartment. The CFW image is a 2.7-nm Z stack, whereas the DIC image is a single plane. B, Cytoplasmic mixing after cell fusion between WT strains containing mRFP1 (PN2832) and eGFP (PN2833). The tip of the mRFP1 strain has fused with a subapical eGFP expressing hyphal cell compartment, followed by cytoplasmic mixing on further hyphal growth. C, Formation of a ladder of hyphal cell fusions following a series of hyphal tip fusions of a growing hypha with the subapical cells of an adjacent hypha $(1,2,3)$ to build an interconnected network. The frequency of fusions is variable. Bar $=10 \mu \mathrm{m}$.
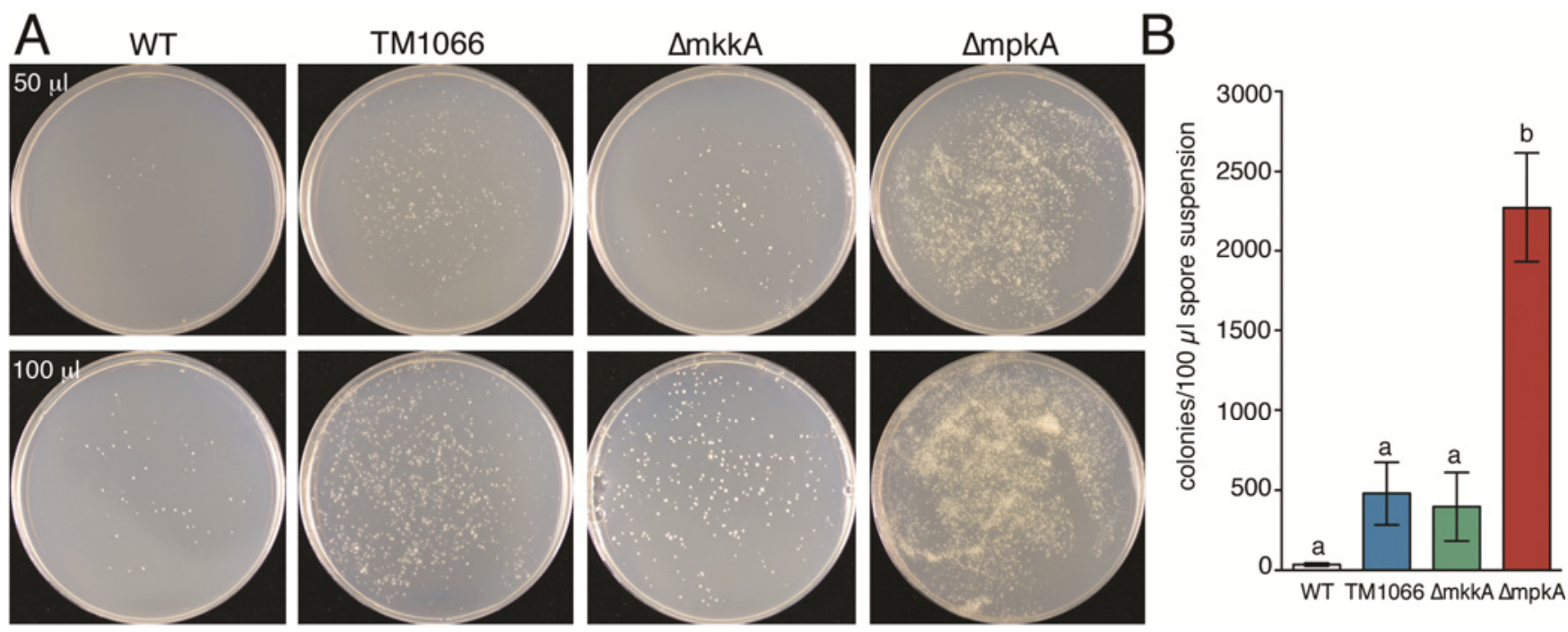

Fig. 3. Epichloë festucae cell-wall integrity MAPK pathway suppresses conidiation under axenic conditions. A, Conidia were isolated from 16 colonies grown on potato dextrose (PD) plates for 6 days, with $50 \mu \mathrm{l}$ (top) and $100 \mu \mathrm{l}$ (bottom) of wild-type (WT), TM1066, $\Delta m k k A$, and $\Delta m p k A$ suspensions spread on PD plates. Colony formation from single spores was photographed and counted after 6 days of growth. B, Mean of spore germination from three independent experiments. Although total colony numbers varied in each independent experiment, conidiation was increased in TM1066 and $\Delta m k k A$ compared with the WT and significantly increased in $\triangle m p k A$. Bars represent mean \pm standard error of the mean $(n=3)$. Letters show significant differences where $P<$ 0.05 , as determined by one-way analysis of variance with Tukey post hoc test. 
five $m k k A$ strains had ectopic integrations and the fifth, $\triangle m k k A 4-2$ (henceforth $\triangle m k k A$; PN2892), a single-site multicopy integration; five of the seven $m p k A$ strains had ectopic integrations but two, $\Delta m p k A 10-8$ (henceforth $\Delta m p k A$, PN2988) and $\triangle m p k A 13-7$, were clean single-copy replacements.

To confirm that MpkA acts downstream of MkkA, its phosphorylation was measured in the wild-type, TM1066, and $\triangle m k k A$ strains (Fig. 5). Two bands were detected in the wild type, corresponding to phosphorylated MpkA at $47 \mathrm{kDa}$ and phosphorylated MpkB (the Fus3 homolog) at $41 \mathrm{kDa}$ (Fig. 5A). The absence of the upper band in TM1066 and $\triangle m k k A$ indicates that MkkA phosphorylates MpkA. We then checked whether the absence of MpkA phosphorylation in the $\Delta m k k A$ and $\triangle m p k A$ mutant backgrounds would affect nuclear localization of MpkA in arthroconidia. These asexual spore-like structures readily form when E. festucae-regenerating protoplasts grow through a regeneration media overlay. Under these conditions of stress, MpkA-eGFP localizes to the nucleus (Cartwright et al. 2014). MpkA-eGFP localized to the nucleus in both the $\triangle m k k A$ and $\triangle m p k A$ mutant backgrounds, demonstrating that phosphorylation of MpkA by MkkA is not necessary for nuclear localization (Fig. 5B).

Several developmental phenotypes have been observed for CWI MAPK mutants in other fungi, including reduced colony radial growth (Maddi et al. 2012; Maerz et al. 2008; Park et al. 2008; Valiante et al. 2009; Xu et al. 1998), defects in conidiation and spore germination (Igbaria et al. 2008; Jeon et al. 2008; Kojima et al. 2002; Mey et al. 2002; Xu et al. 1998), an absence of cell-cell fusion (Lichius et al. 2012; Maddi et al. 2012; Maerz et al. 2008), and impaired sexual fruiting body development (Hou et al. 2002; Kicka and Silar 2004; Lichius et al. 2012; Maddi et al. 2012; Maerz et al. 2008; Park et al. 2008; Xu et al. 1998). Radial growth of E. festucae $\Delta m k k A$ and $\triangle m p k A$ mutants on PDA and water agar was normal and the colony morphology of both mutants was identical (Fig. 6A) and indistinguishable from that of the wild-type strain (Fig. 1C). Light microscopy analysis showed that both $\triangle m k k A$ and $\Delta m p k A$ hyphae grew as attached bundles with branching restricted to

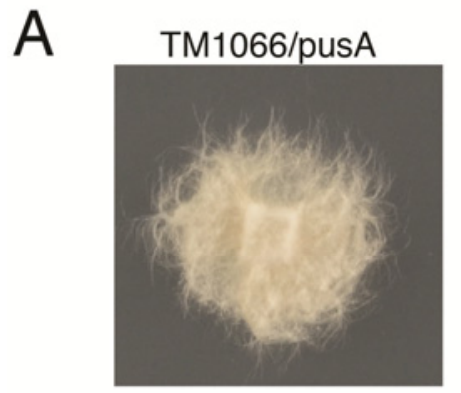

B
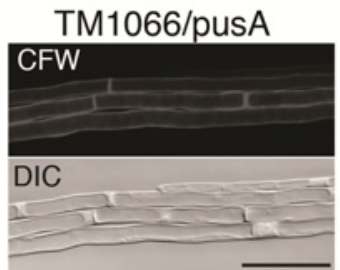

C
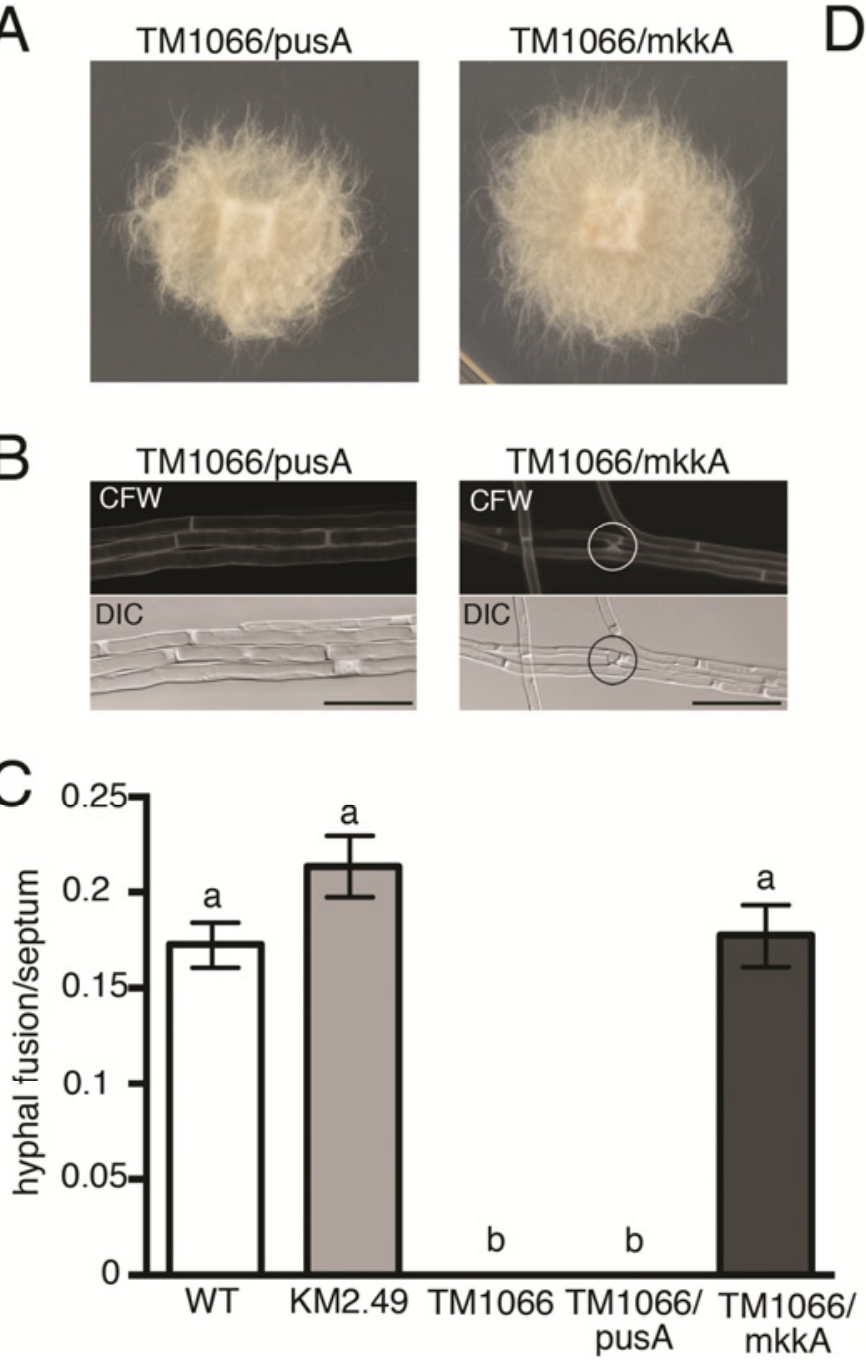
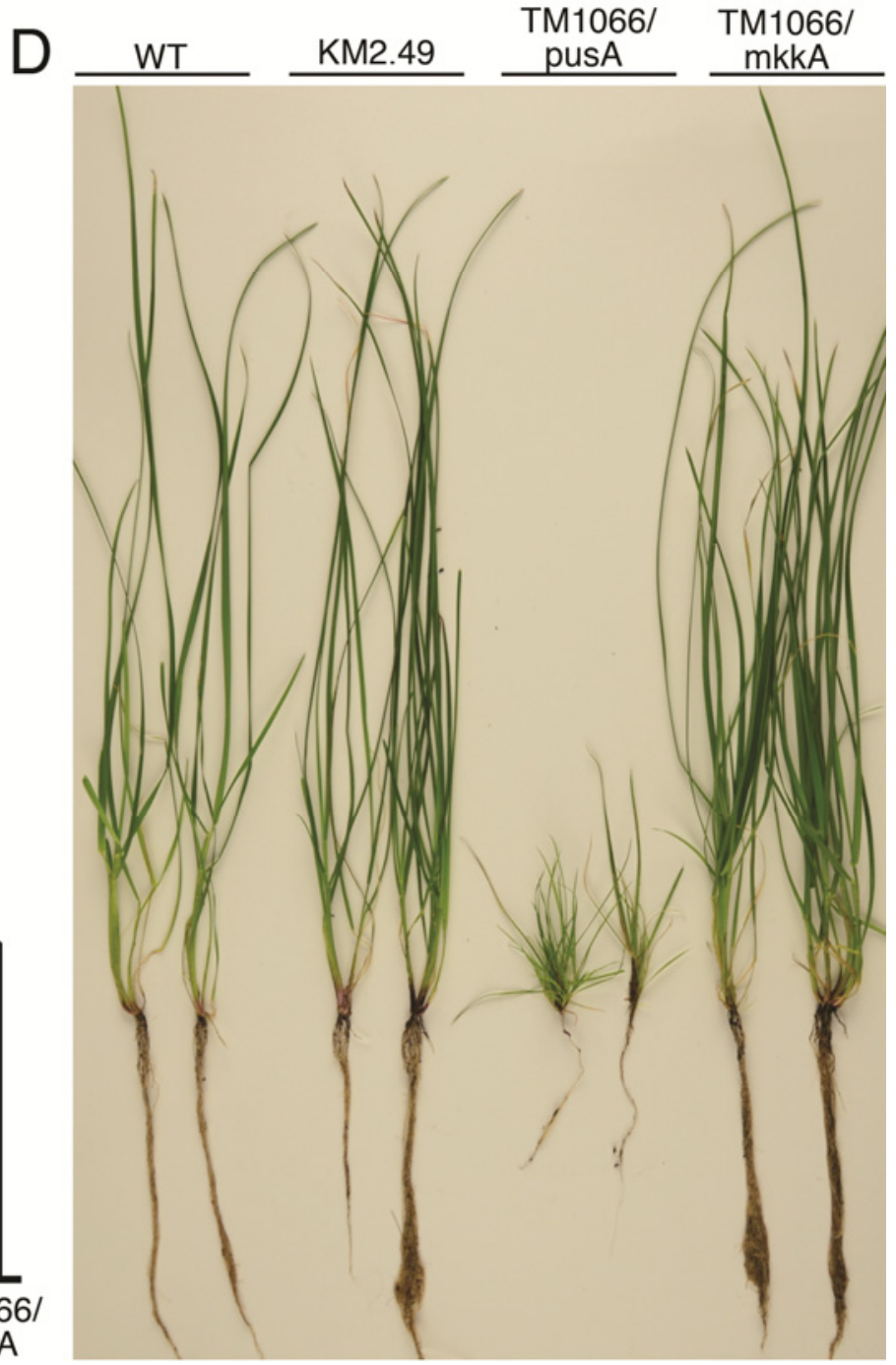

Fig. 4. Complementation with $m k k A$ but not pusA rescues the cell fusion and plant symbiosis defects of TM1066. A, Colony morphology of Epichlö̈ festucae mutants TM1066/pusA (PN2875) and TM1066/mkkA (PN2989) grown on potato dextrose agar for 5 days. B, Confocal laser-scanning and differential interference contrast microscopy images of hyphal anastomosis in TM1066/mkkA but not TM1066/pusA cultures grown on water agar coated slides and stained with Calcofluor white $(\mathrm{CFW})$. Bar $=20 \mu \mathrm{m}$. C, Number of hyphal fusions per septa beginning from the first contact point. Cultures of E. festucae wild-type (WT) PltmM-gusA knock-in strain KM2.49, T-DNA mutant TM1066, and strain TM1066 containing pusA (TM1066/pusA) or mkkA (TM1066/mkkA) were grown on water-agar-coated slides, stained with CFW, and 10 fusion ladders each from four colonies were counted under the fluorescence microscope. Bars represent mean \pm standard error of the mean $(n=40)$. Letters show significant differences determined by one-way analysis of variance $(P<0.05)$. D, Phenotype of perennial ryegrass plants infected with E. festucae WT, KM2.49, TM1066/pusA, and TM1066/mkkA. Photograph was taken 10 weeks postinoculation. 
the subapical region, growth phenotypes similar to that of the wild type. As observed for TM1066, both mutants were defective in hyphal cell-cell fusion and formed intrahyphal hyphae, although the latter phenotype was observed more frequently in older cultures (Fig. 6B). To confirm the defect in cell-cell fusion, wild-type and mutant strains were transformed with constructs containing either eGFP or mRFP1 and analyzed for cell fusion events between the different strains after co-cultivation on water-agar-coated slides (Fig. 7). Whereas cytoplasmic mixing was observed between Fl1-eGFP and Fl1-mRFP1, no cytoplasmic mixing was observed between $\triangle m k k A$-eGFP $\times \Delta m k k A$ mRFP and $\triangle m p k A$-eGFP $\times \triangle m p k A-m R F P 1$ or in mutant strains co-cultivated with the wild type.

Conidiation was enhanced in both $\triangle m k k A$ and $\triangle m p k A$, with the frequency in the former similar to that seen in TM1066, whereas the frequency of conidiation in the latter was five times greater than that of $\triangle m k k A$ and TM1066 (Fig. 3). The frequency of conidia germination appeared to be nutrient independent because similar numbers of colonies arose from spore suspensions spread on PDA as on water agar. Likewise, germ
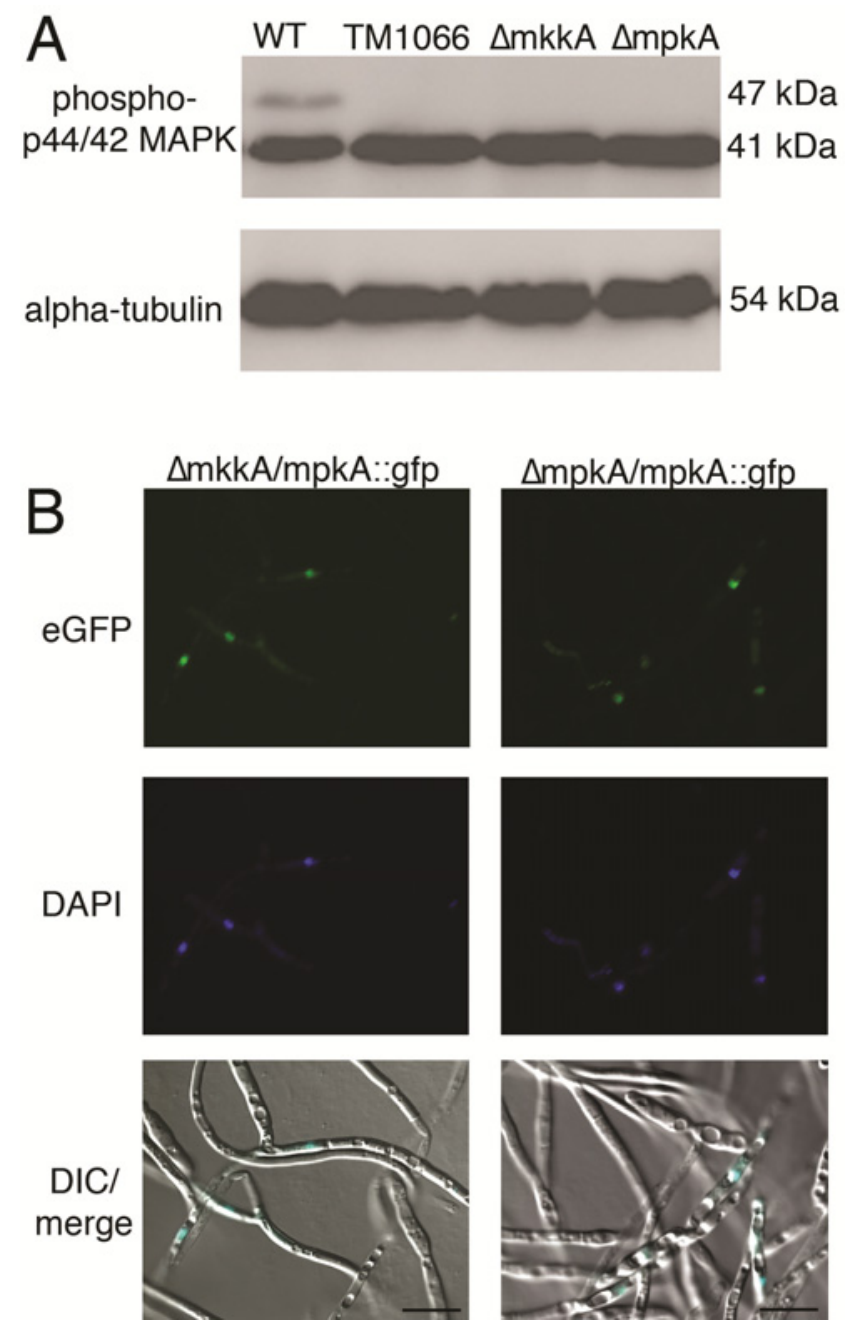

Fig. 5. Phosphorylation and localization of MpkA. A, Western blot analysis of the wild type (WT) and TM1066, $\Delta m k k A$, and $\triangle m p k A$ mutants. Phosphorylated MpkA (47 kDa) and MpkB (41 kDa) were detected using anti-phospho p42/p44 MAPK antibodies. The membrane was reprobed with anti- $\alpha$ tubulin as loading control. B, Localization of MpkA-eGFP in regenerating hyphae after protoplasting. $\triangle m k k A$ and $\triangle m p k A$ cultures expressing MpkA-eGFP and stained with 4',6-diamidino-2-phenylindole were examined using confocal laser-scanning and differential interference contrast microscopy during growth through the antibiotic overlay layer. $\mathrm{Bar}=10 \mu \mathrm{m}$. tube morphology was the same under both growth conditions, with most conidia forming unipolar germ tubes upon germination (Fig. 6C). Occasionally, we observed concerted bipolar germ tube emergence in the mutants. Although this phenotype has not yet been observed in the wild-type strain, this may be due to the very low rate of sporulation that occurs in Fl1, making it more difficult to find them. Conidiophores in Fl1 frequently arise from hyphae that are organized as coil-like structures; laterals from these coils give rise to conidiophores from which holoblastic conidiation occurs. Close microscopic examination of the coil-like structures in the $\triangle m p k A$ and $\triangle m k k A$ mutants (Fig. 6C) revealed microcyclic conidiation in both mutants, a process previously reported for E. typhina ascospore germination (Bacon and Hinton 1991), where conidiophores arise directly from germinating spores to form more spores. Microcyclic conidiation was more frequent in $\triangle m p k A$ than in $\triangle m k k A$ and may account for the greater rate of conidiation observed in this mutant (Fig. 3).

\section{The CWI MAPK pathway is dispensable for growth under stress conditions.}

Deletion of the CWI MAPKK or MAPK in yeast and filamentous fungi generally results in an increased sensitivity to cell-wall stress agents and cell-wall-degrading enzymes (Hou et al. 2002; Kojima et al. 2002; Mey et al. 2002; Valiante et al. 2009). Therefore, we tested the effect of a range of stress agents on the vegetative growth of E. festucae TM1066 compared with KM2.49 and the $\triangle m k k A$ and $\triangle m p k A$ mutants compared with the wild-type strain Fl1 (Supplementary Fig. S6). Surprisingly, E. festucae $m k k A$ and $m p k A$ mutants grew as well as the wild type on media containing the chitin synthase inhibitor nikkomycin $\mathrm{Z}$ and the cell-wall stress agents Calcofluor white and Congo red. Treatment with sodium dodecyl sulfate (SDS), a chemical known to readily lyse cells with membrane defects, also had no effect on the growth rate of mutants over and above that seen with the wild type. Addition of caffeine, an alkaloid known to trigger activation of the CWI pathway in yeast, did not affect growth of mutants. In yeast, the CWI MAPK pathway is essential for response to high temperature but the growth rate of E. festucae $\Delta m k k A$ and $\triangle m p k A$ mutants at $30^{\circ} \mathrm{C}$ was the same as the wild type. We also tested sensitivity to osmotic and salt stress using 0.7 $\mathrm{mM}$ sorbitol and $0.3 \mathrm{mM} \mathrm{NaCl}$ but neither of these treatments affected the growth of mutants compared with the wild type. Treatment with the oxidative stress agents $\mathrm{H}_{2} \mathrm{O}_{2}$, diamide, and menadione revealed no differences between the growth of mutants and the wild type. These results suggest that E. festucae has a highly redundant system for protection against cell wall and other stresses.

\section{The $E$. festucae CWI MAPK pathway is crucial for plant symbiosis.}

Both $\triangle m k k A$ and $\triangle m p k A$ had an L. perenne symbiotic interaction phenotype very similar to TM1066; only a small number of plants were infected (4 to 15\%) and these were severely stunted and underwent premature senescence (Fig. 6D). Hyphal growth within the pseudostem of these leaves was examined by fluorescence confocal microscopy (Fig. 8) and TEM (Fig. 9). In contrast to the restrictive growth of the wild-type strain, hyphae of the $\triangle m k k A$ and $\triangle m p k A$ mutants were much more prolific within the leaf tissue, had an irregular pattern of growth, and frequently formed highly convoluted structures (Fig. 8A4 and A6). Whereas just the septa of the wild-type hyphae stained with AF488-WGA, in the mutant hyphae, large patches of AF488 fluorescence (imaged in blue) were visible, suggesting a change in structure or composition of the cell wall resulting in greater accessibility of the cell-wall chitin to 
the fluorophore-labeled lectin (Fig. 8B1 and B3). The increased fluorescence of the host cells, particularly in tissues infected with $\triangle m p k A$, may be indicative of a defense response which could be a consequence of the change in cell-wall structure or composition of the mutant hyphae or to the degradation of host chloroplasts (Fig. 8A5 and B4). Mutant hyphae don't appear to fuse but, instead, grow alongside one another to form bundles of hyphae in the intercellular spaces as well as repeatedly fold around one another to form highly convoluted structures (Fig. 8A4, A5, B2, and B4). These structures were more frequently found adjacent to vascular bundles, where there is a greater proliferation of the mutant hyphae compared with wild-type hyphae.

As observed for TM1066, the $\triangle m k k A$ and $\triangle m p k A$ mutants extensively colonized the vascular bundles of the host tissue (Fig. 9A) and formed intrahyphal hyphae (Fig. 9C). Hyphae within the vascular bundles were more cytoplasmically dense than those growing outside these tissues (Fig. 9A and B). The number of hyphae in the intercellular space was much greater in the mutants than the wild type (Supplementary Fig. S7). A close examination of the cell walls of the mutant revealed the absence of the darkly staining outer layer in some hypha that was present in the wild type (Fig. 9D), a change consistent with the increased fluorescence found with AF488-WGA staining and increased frequency of ruptured cells of the mutant hyphae (Fig. 8B1, B3, and A4).

To confirm that the $m k k A$ and $m p k A$ deletions were responsible for the altered symbiotic interaction phenotype and cell fusion defect, plasmids pYR33 and pYR32, containing the fulllength $m k k A$ and $m p k A$ genes under the control of their native promoters and terminators, were transformed into protoplasts of $\triangle m k k A$ and $\triangle m p k A$, respectively. These transformants estab-
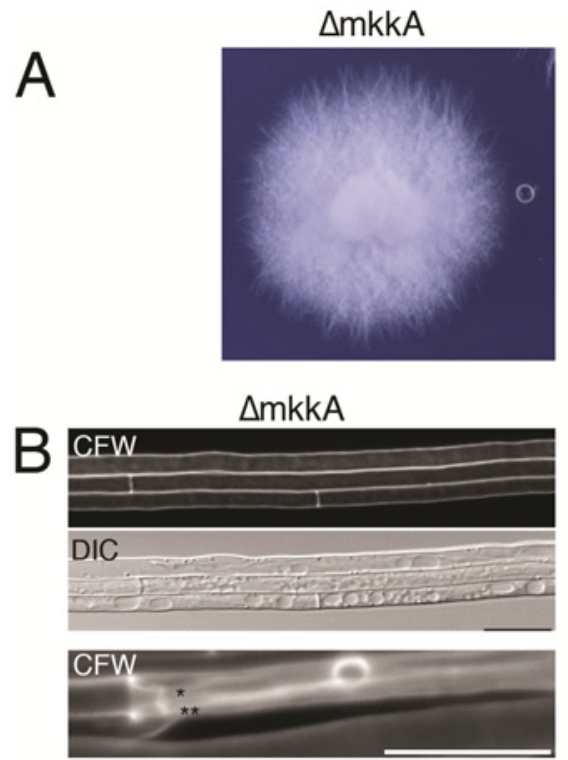

C
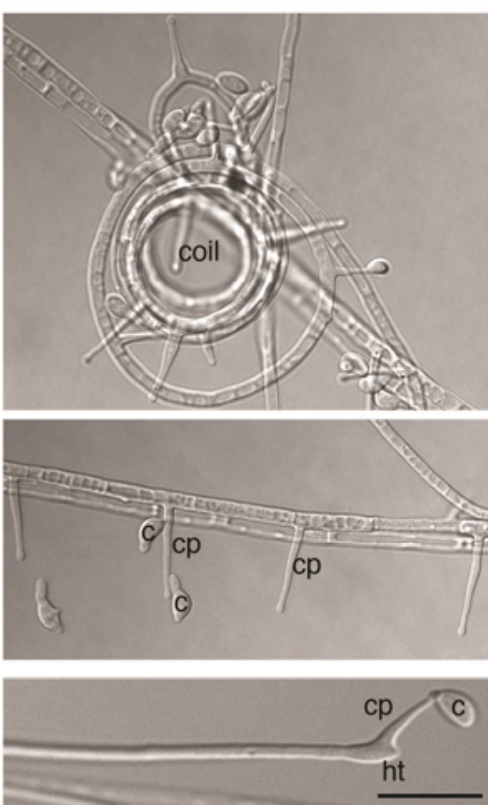
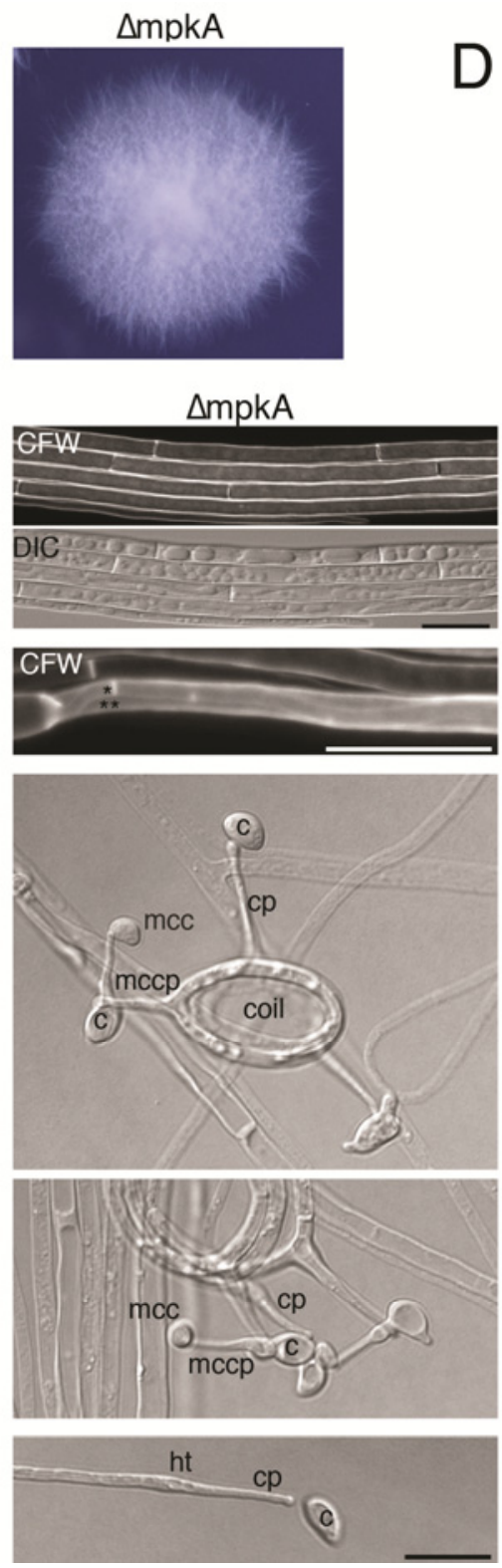

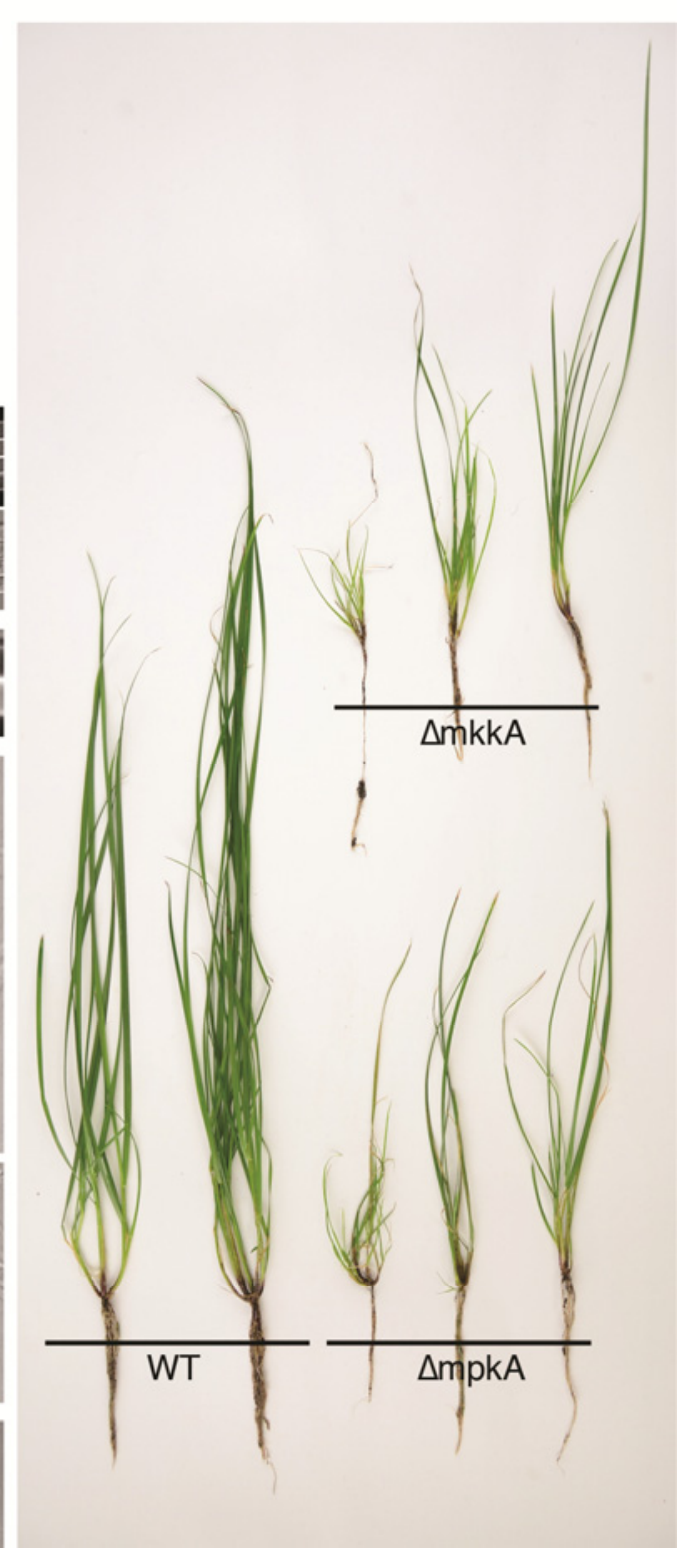

Fig. 6. Strain $\triangle m k k A$ and $\triangle m p k A$ culture and in planta phenotypes. A, Culture phenotype of Epichloë festucae cell-wall integrity MAPK mutants $\Delta m k k A$ and $\triangle m p k A$ grown on potato dextrose agar for 6 days. B, Confocal laser-scanning and differential interference contrast (DIC) microscopy images of hyphal morphology of $E$. festucae grown on water agar (1.5\%) for 6 days. Cultures were stained with Calcofluor white (CFW) as indicated; $\Delta m k k A$ and $\Delta m p k A$ are fusion negative and form intrahyphal hyphae. Symbols: $*=$ inner hypha and $* *=$ outer hypha. Bar $=10 \mu \mathrm{m}$. C, DIC microscopy images of $\Delta m k k A$ and $\Delta m p k A$ hyperconidiation and microcyclic conidiation. Symbols: $\mathrm{c}=$ conidium, $\mathrm{cp}=$ conidiophore , mcc $=$ microcyclic conidium, mccp $=$ microcyclic conidiophore, ht = hyphal tip. Bar $=10 \mu \mathrm{m}$. D, Phenotype of perennial ryegrass plants infected with E. festucae wild-type and $\Delta m k k A$ and $\Delta m p k A$ mutants. Photograph was taken 10 weeks postinoculation. 
lished a symbiotic interaction with perennial ryegrass like the wild type (Fig. 10A) and regained the ability to fuse in culture (Fig. 10B and C).

\section{DISCUSSION}

The CWI pathway is one of three conserved MAPK pathways found in filamentous fungi for transducing signals, perceived by upstream membrane localized environmental sensors, to downstream effectors (Levin 2005; Rispail et al. 2009). This particular signaling cascade is responsible for mediating changes to the cell wall during certain stages in the cell cycle and in response to various forms of stress. In filamentous fungi, this pathway is important for a number of cellular developmental processes, including hyphal fusion (Lichius et al. 2012; Maddi et al. 2012; Maerz et al. 2008), conidiation (Igbaria et al. 2008; Jeon et al. 2008; Kojima et al. 2002; Mey et al. 2002; Xu et al. 1998), appressorium development (Igbaria et al. 2008; Jeon et al. 2008; Xu et al. 1998), plant infection (Hou et al. 2002; Igbaria et al. 2008; Jeon et al. 2008; Kojima et al. 2002; Mey et al. 2002; Xu et al. 1998), and female fertility and fruiting body development (Hou et al. 2002; Kicka and Silar 2004; Lichius et al. 2012; Maddi et al. 2012; Maerz et al. 2008; Park et al. 2008; Xu et al. 1998). Here, we demonstrate for the first time a key role for this signaling pathway in establishing and maintaining a mutualistic symbiotic interaction between $E$. festucae and its host, L. perenne. The inability of E. festucae CWI mutants to undergo hyphal fusion appears to be a crucial developmental defect that leads to breakdown of this fungus-plant symbiotic interaction.

Homologues of nearly all components of the $S$. cerevisiae CWI pathway have been identified in the genomes of $E$. festucae and other filamentous fungi, including the threetiered kinase module comprising a MAPKKK, a MAPKK, and the MAPK (Eaton et al. 2011; Rispail et al. 2009). Complementation analysis demonstrated that deletion of the $E$. festucae mkkA (MKK1), rather than pusA (Chan and Huang 2009) was responsible for the culture and symbiosis phenotypes observed for the A. tumefaciens T-DNA-induced deletion mutant, TM1066. Gene deletions or genome rearrangements appear to be a common outcome of T-DNA-induced mutagenesis in filamentous fungi (Choi et al. 2007; Jeon et al. 2007). A targeted deletion of $m k k A$ recapitulated the phenotypes observed for TM1066, as did deletion of the downstream mpkA, providing strong support that MkkA and MpkA are components of the same MAPK pathway. This was confirmed by the lack of MpkA phosphorylation in the $\Delta m k k A$ background.
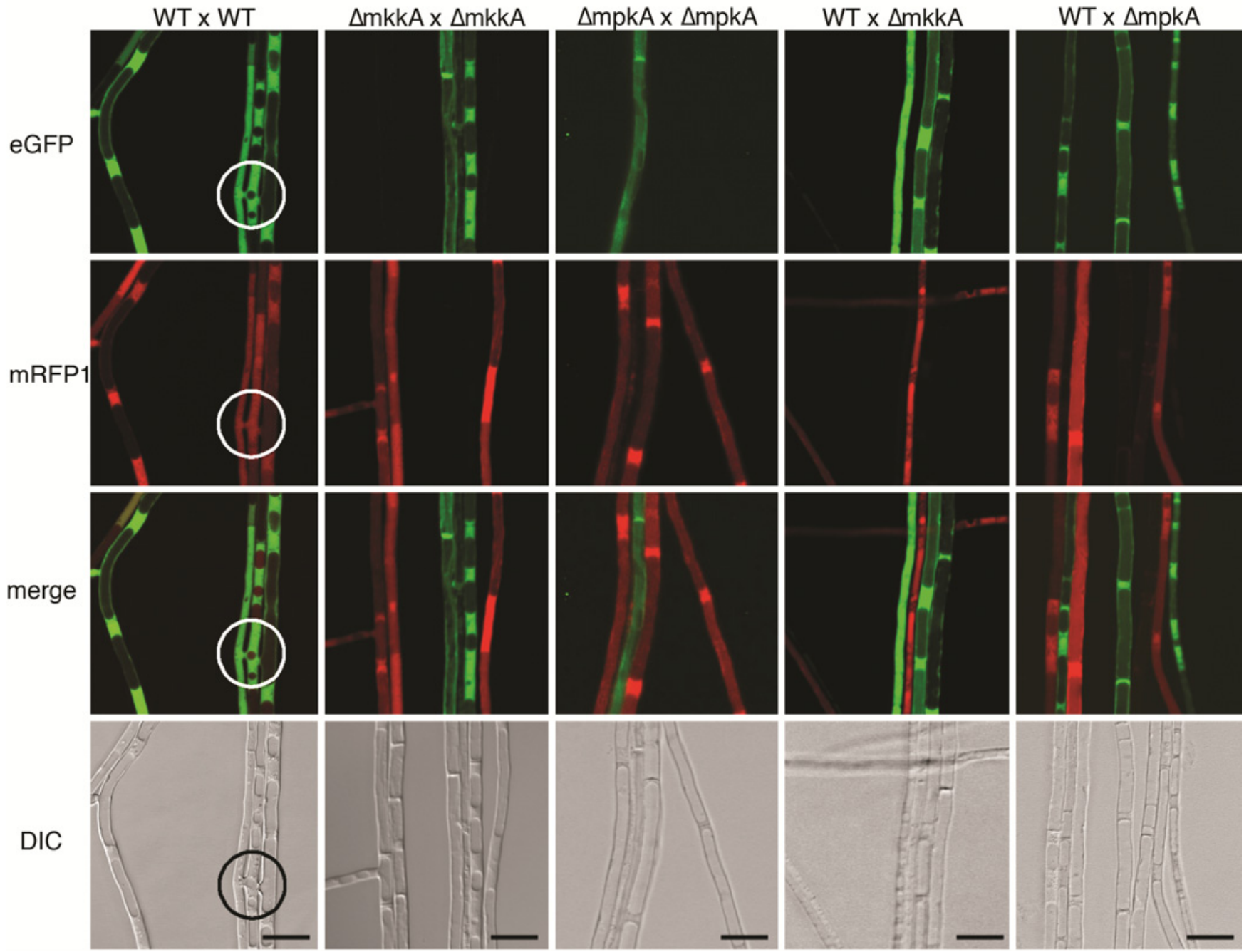

Fig. 7. Strain $\triangle m k k A$ and $\triangle m p k A$ cell-cell fusion culture phenotypes. Epichloë festucae wild-type (WT) and cell-wall integrity mutants $\Delta m k k A$ and $\Delta m p k A$, expressing either eGFP (WT: PN2833; $\Delta m k k A$ : PN2996 $\Delta m p k A$ : PN2998) or mRFP1 (WT: PN2832; $\Delta m k k A$ : PN2997 $\Delta m p k A$ : PN2999), were co-cultured on water agar for 5 days either with themselves or in combination with the WT and then examined for cell-cell fusion by confocal microscopy. Hyphal anastomoses (circled) were detected as appearance of both fluorescent proteins in the same hyphal cell in the WT-WT combination. No anastomoses were observed in the mutant-mutant and mutant-WT combinations. Bar $=10 \mu \mathrm{m}$. 
Both $m k k A$ and $m p k A$ mutants are defective in cell-cell fusion when grown on water agar, a culture phenotype observed for four other E. festucae mutants that have a severe plant interaction phenotype, including $\triangle$ noxA and $\Delta$ noxR, genes that en- code components of the Nox complex (Kayano et al. 2013); $\triangle p r o A$, a gene encoding a $\mathrm{Zn}(\mathrm{II})_{2} \mathrm{Cys}_{6}$ transcription factor (Tanaka et al. 2013); and $\Delta s o$, a gene of unknown function (Charlton et al. 2012). Hyphal fusion is an important mecha-
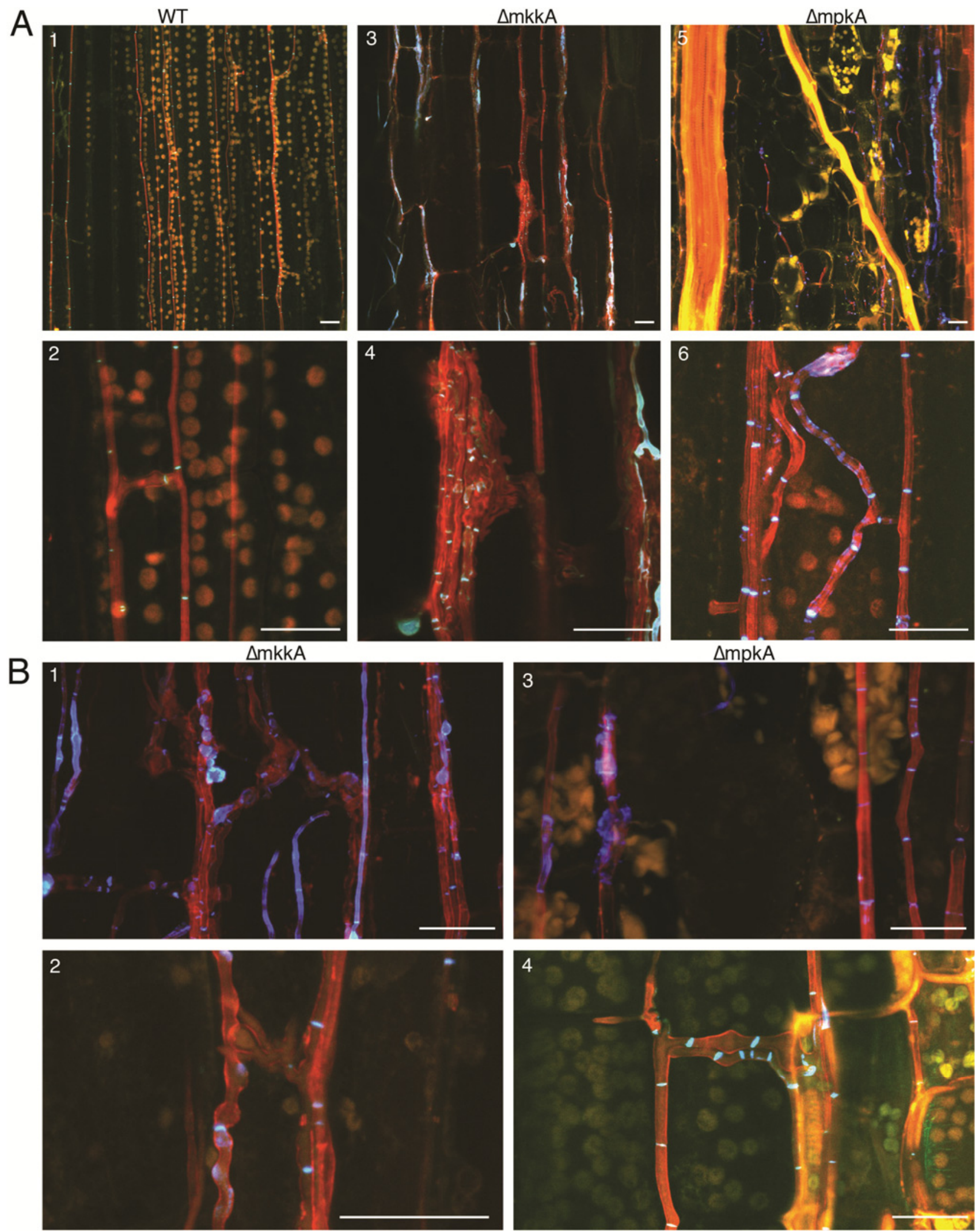

Fig. 8. Strain $\triangle m k k A$ and $\triangle m p k A$ in planta cellular phenotypes. Confocal depth series images of aniline blue- or Alexafluor 488 WGA-stained Lolium perenne leaf sheath tissue infected with the wild type (WT), $\Delta m k k A$, and $\Delta m p k A$. Hyphae stained with aniline blue appear as red and chitin in septa and cell wall stained with Alexafluor 488-WGA as blue. Chloroplasts of plant cells appear as light orange. Leaf images were captured 7 weeks after inoculation. Bar $=20 \mu \mathrm{m}$. 


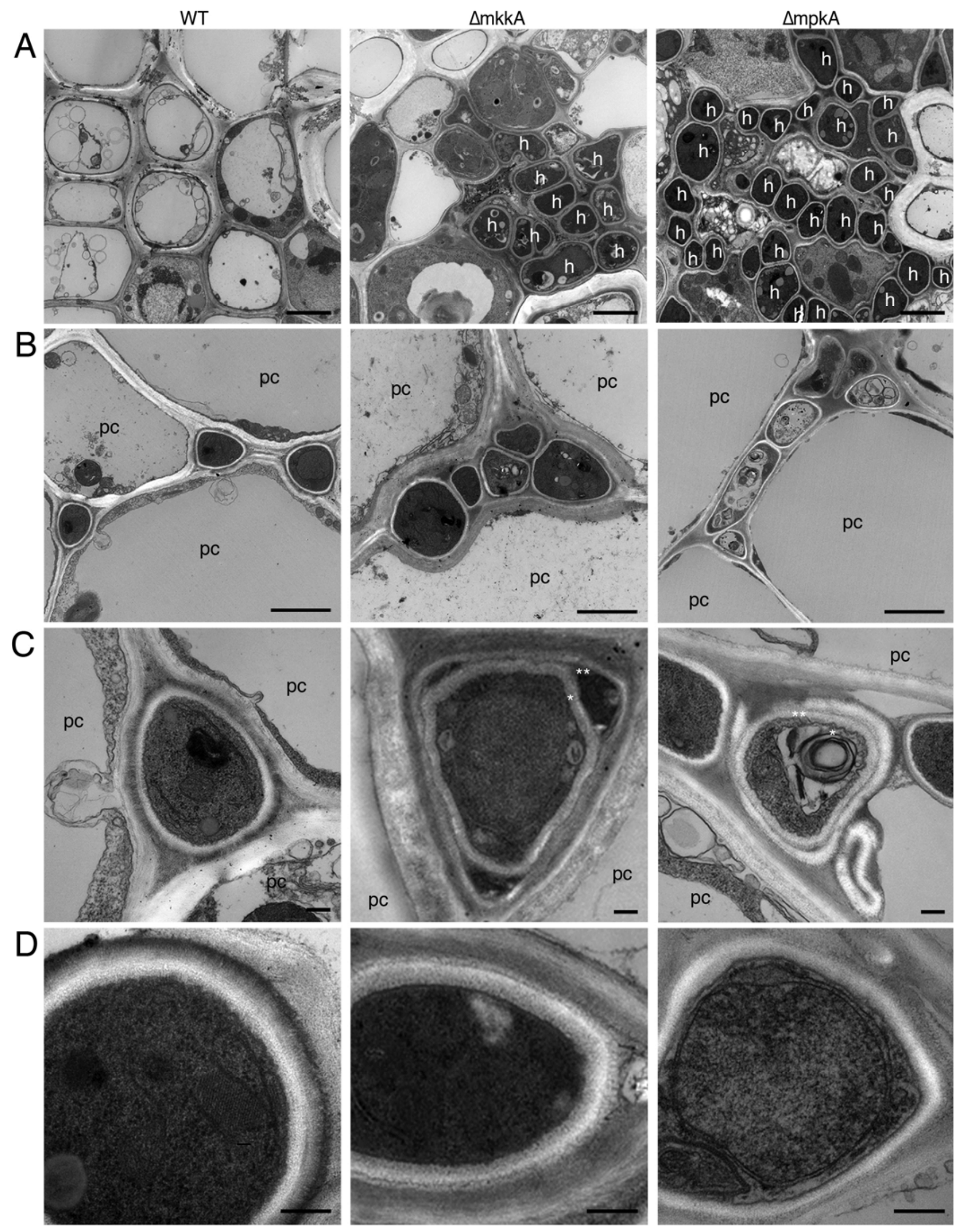

Fig. 9. Strain $\triangle m k k A$ and $\triangle m p k A$ in planta cellular phenotypes compared with the wild type (WT). Transmission electron micrographs of cross-sections of Lolium perenne pseudostems infected with the WT endophyte and $\triangle m k k A$ and $\triangle m p k A$ deletion mutants. A, Hyphae in vascular bundles of mutant-infected plants. B, Hyphal colonization of plant intercellular spaces. C, Intrahyphal hyphae formed by $\triangle m k k A$ and $\Delta m p k A$ strains. D, Close up of cell walls of WT and $\Delta m k k A$ and $\Delta m p k A$ strains. Symbols: $*=$ inner hypha, $* *=$ outer hyphae, $\mathrm{h}=$ hypha, $\mathrm{pc}=$ plant cell. $\mathrm{Bar}=2 \mu \mathrm{m}(\mathrm{A}$ and $\mathrm{B})$ or $0.2 \mu \mathrm{m}(\mathrm{C}$ and $\mathrm{D})$. 
nism for establishment of a colony hyphal network, enabling sharing of resources and interhyphal communication (Fricker et al. 2007; Leeder et al. 2013; Read et al. 2009; Simonin et al. 2010). In $N$. crassa, there are two developmental stages where fusion is important. When conidia germinate, they initially put out small germ tubes called CATs, which home toward one another, then fuse (Roca et al. 2005a and b; Read et al. 2009, 2010). As the colony size increases, lateral hyphal branches also home and fuse, allowing the rapid development of an interconnected hyphal network (Hickey et al. 2002; Read et al. 2009, 2010). Many genes defective in hyphal anastomosis (ham) have been identified, principally by screening for a defect in heterokaryon formation (Aldabbous et al. 2010; Fu et al. 2011). Formation of CATs in $N$. crassa involves oscillation of key signaling network proteins at the tips of hyphae about to fuse, the paradigm for this being the oscillation of $\mathrm{SO}$, a protein of unknown function, with MAK-2, the MAPK of the pheromone response pathway (Fleissner et al. 2009).

In contrast to $N$. crassa, development of conidia in axenic cultures of E. festucae is rather sparse, making it technically difficult to study colony establishment from germinating conidia. Instead, we use small blocks of vegetative hyphae as the initial inoculum. A distinct feature of E. festucae hyphal growth under these nonsymbiotic conditions is the adherence of individual hyphae to one another to form bundles of hyphae, interconnected by branches, that radiate from the center of the colony rather than the highly branched single hyphae network observed for $N$. crassa and other filamentous fungi (Scott et al. 2012). A distinctive feature of this pattern of growth is the formation of lateral hyphal fusions, observed as small pegs between adjacent hyphae, rather than the more typical tip-to-tip fusions from lateral branches. However, the location of these hyphal connections on the lateral edges of the cells belies the origin of the underlying hyphal fusion mechanism. Microscopy of growing hyphae revealed that hyphal anastomosis in $E$. festucae occurs by fusion of the tip of a growing hyphal cell with the lateral edge of a subapical adjacent hypha cell (socalled tip-to-side fusion) (Hickey et al. 2002), followed by repolarization of the tip cell and ongoing tip growth: a fusion process very similar to that observed in $F$. oxysporum (Ruiz-
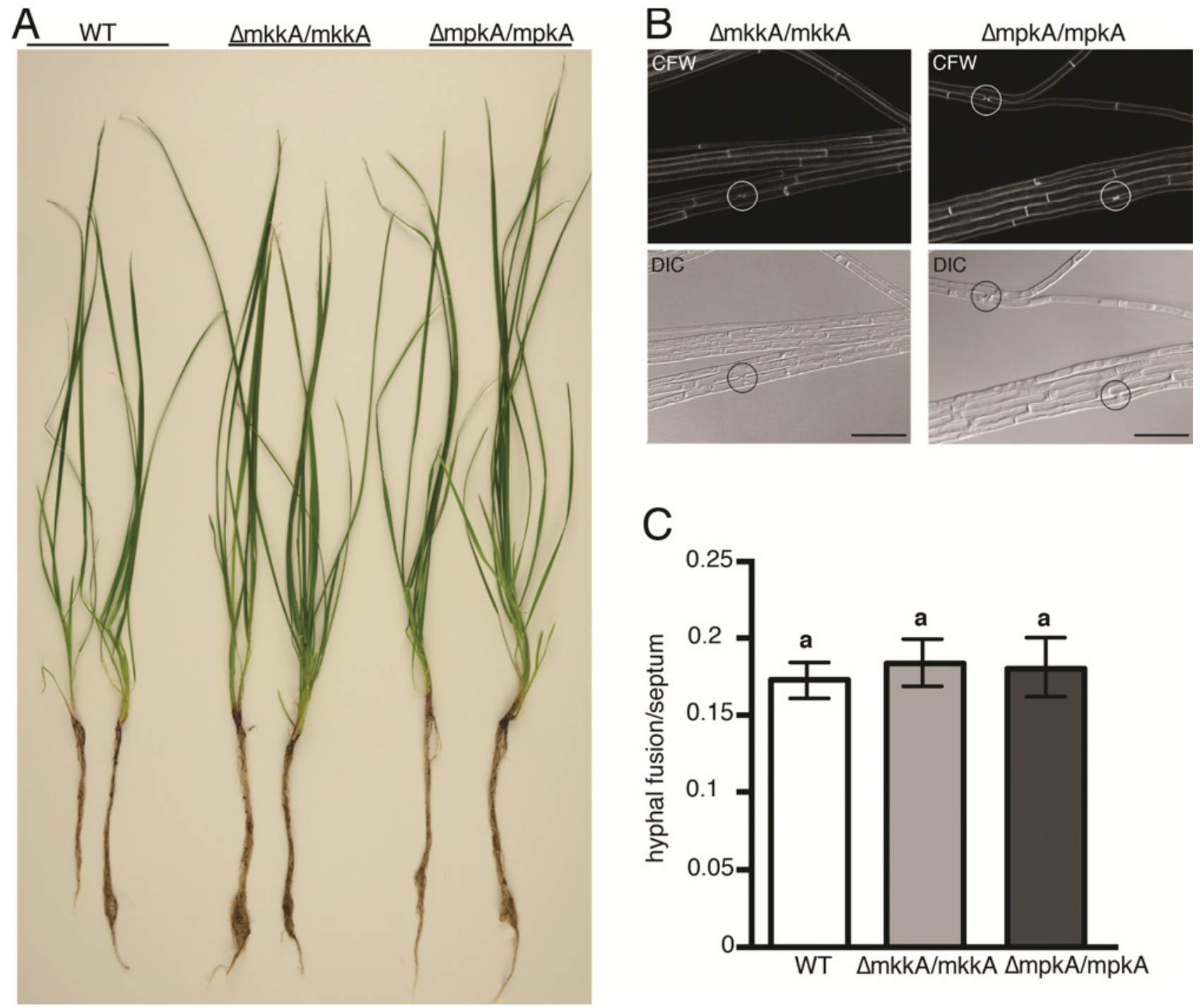

Fig. 10. In planta complementation and fusion counts of $\triangle m k k A$ and $\triangle m p k A$ complementation strains compared with the wild type (WT). A, Phenotype of perennial ryegrass plants infected with Epichlö festucae WT and complemented deletion mutants of $\Delta m k k A(\Delta m k k A / m k k A)$ and $\Delta m p k A(\Delta m p k A / m p k A)$. Photographs were taken 10 weeks postinoculation. B, Confocal laser-scanning and differential interference contrast microscopy images of hyphal anastomosis in complemented strains of cultures grown on water-agar-coated slides stained with Calcofluor white (CFW). C, Number of hyphal anastomosis of E. festucae WT and complemented strains. Cultures grown on water-agar-coated slides were stained with $\mathrm{CFW}$ and 10 fusion ladders each from four colonies were counted under the fluorescence microscope. Bars represent mean \pm standard error of the mean $(n=40)$. Letters show significant differences determined by one-way analysis of variance $(P<0.05)$. 
Roldán et al. 2010). A series of sequential fusions by the tip of actively growing hypha with a subapical cell of an adjacent hypha gives rise to a ladder-like hyphal network.

Another striking phenotype of the $m k k A$ and $m p k A$ mutants was the formation of intrahyphal hyphae. These structures have been observed in a number of naturally occurring fungi within the ascomycetes and are thought to form under conditions of hyphal stress or in response to cell damage (Buller 1933; Calonge 1968; Chan and Stephen 1967). A very detailed TEM analysis of intrahyphal hyphae in Sclerotinia fructigena provides important insights as to how these structures arise from parental hyphae at the ultrastructural level (Calonge 1968). A secondary cell wall is formed in the parent cell that is closely attached to the outer wall. From here, the new hypha pushes through the plugged septal pore into the adjacent hypha. The internal hypha is able to form septa and eventually exits the enveloping hypha. Interestingly, intrahyphal hyphae have also been observed in other mutants that perturb CWI, including Aspergillus nidulans csmA, encoding a class V chitin synthase (Horiuchi et al. 1999), and N. crassa gpip3 and gpit-1, encoding the glycophosphatidylinositol (GPI) anchor biosynthetic pathway enzymes, GPI $N$-acetylglucosamine transferase and GPI transaminase (Bowman et al. 2006). The increased sensitivity of these mutants to cell-wall stress agents such as Congo red and Calcofluor white is indicative of defects in CWI. Although the E. festucae mkkA and $m p k A$ mutants were not defective in aerial growth, were not inhibited by the chitin synthase inhibitor nikkomycin Z, and were tolerant to a wide range of cell-wall stress agents, including Calcofluor white, Congo red, SDS, and caffeine, the propensity to form intrahyphal hyphae is indicative of an underlying defect in CWI.

The mechanisms underlying the formation of intrahyphal hyphae are not yet understood but studies on Woronin body biogenesis and cellular dynamics of these organelles are providing some important insights. Woronin bodies are important organelles that seal the septal pore in response to wounding and are found exclusively within the filamentous ascomycetes (Pezizomycotina). A key component of this organelle is the Woronin body sorting complex (WSC), which is required for both biogenesis and partitioning of the organelle within the cell (Liu et al. 2008). Deletion of wsc in $N$. crassa increases the formation of hexagonal rods of the HEX structural protein (HEX assemblies) at hyphal tips but depletes assemblies in subapical compartments. This mutation also leads to formation of intrahyphal hyphae, a response triggered by septal pore sealing in damaged hyphae. Both hex and pexl4 mutants fully suppress these wsc growth phenotypes. Intrahyphal hyphae are also observed in a mutant of the septal pore-associated (SPA) protein, SPA9 (Lai et al. 2012). This protein is one of a set of nonhomologous proteins that localize as rings at the septal pore. Upon cellular wounding, a Woronin body is translocated to the closest septal pore, where it associates with the SPA proteins to form an occlusion complex. Inactivation of SPA9 appears to trigger aberrant activation of Woronin bodies, leading to a reduction in radial growth and formation of intrahyphal hyphae.

While hyphal anastomosis on water agar is blocked in the $m k k A$ and $m p k A$ mutants, conidiation is derepressed, a phenotype also observed for $\triangle$ nox $A, \Delta n o x A / B$, and $\triangle p r o A$ (Kayano et al. 2013; Tanaka et al. 2013). These common culture phenotypes suggest that the NoxA Nox complex, ProA, and the CWI MAPK pathway are all components of a cellular regulatory network that controls hyphal fusion and conidiation. In contrast, disruption of components of the CWI MAPK pathway in most other filamentous fungi results in either reduction or complete abolition of conidiation (Igbaria et al. 2008; Jeon et al. 2008; Kojima et al. 2002; Mey et al. 2002; Xu et al. 1998); an exception being $N$. crassa CWI mutants, which show an increase in arthroconidiation (Maerz et al. 2008; Park et al. 2008). Light and scanning electron microscopy examination of asexual development in E. festucae suggests that conidiophores arise from individual hyphae and hyphae organized as coiled structures (Scott et al. 2012). In this study, these coiled structures were more frequently observed in the $m k k A$ and $m p k A$ mutants than in the wild-type strain. A close examination of the conidiophores arising from these structures revealed that many of the conidia released immediately germinate to give rise to a new conidiophore rather than vegetative hyphae, a process known as microcycle conidiation (Anderson and Smith 1971). The greater frequency of microcycle conidiation in the $m p k A$ mutant probably accounts for the greater number of conidia observed for this mutant compared with the $m k k A$ mutant. There are numerous reports of microcycle conidiation by fungi grown under laboratory conditions but the role of this process in nature is not clear (Hanlin 1994; Smith et al. 1981). Bacon and Hinton (1991) proposed that microcycle conidiation might be a mechanism for increasing spore numbers, thereby enhancing plant infection. Floral infection by conidia appears to be the main route for horizontal transfer of Epichloë and Claviceps species in nature (Chung and Schardl 1997; Pazantova et al. 1978). In the case of E. typhina, ascospores released by perithecia from stromata on the leaves of the grass host germinate to produce conidia rather than vegetative hyphae and these conidia, in turn, undergo microcycle conidiation to generate large numbers of conidia which infect the ovules of florets (Bacon and Hinton 1991). Once the hyphae colonize the vegetative tissues of the host, conidiation is suppressed. Our work here suggests that the CWI MAPK pathway is an important signaling system for controlling conidiophore development and microcycle conidiation in E. festucae. Based on our observation that the $m p k A$ mutant produces significantly more conidia than the $m k k A$ mutant, and the fact that MpkA phosphorylation but not localization to the nuclei of arthroconidia is MkkA dependent, we propose that nuclear localization of MpkA is more important for repression of conidiation than its phosphorylation status. In contrast, conidiation in $F$. graminearum seems to be regulated by Mkk1 (=MkkA/MEK1) independent of the downstream-acting MpkA homolog Mgv1 (Yun et al. 2013).

The severe host interaction phenotype observed for the $m k k A$ and $m p k A$ mutants was very similar to that previously reported for the E. festucae $\Delta$ noxA, $\Delta$ noxR, $\triangle r a c A, \triangle p r o A$, and $\Delta$ so mutants (Charlton et al. 2012; Takemoto et al. 2006; Tanaka et al. 2006, 2008, 2013); seedlings either died or formed severely stunted plants that underwent premature senescence. This host phenotype may be the result of an upregulation of host defense genes, including the pathogenesis-response (PR) genes, as previously observed for plants infected with $E$. festucae stressactivated MAPK ( $\operatorname{sakA}$ ) and Nox (noxA) mutants (Eaton et al. 2010; Tanaka et al. 2006). Instead of the restrictive pattern of hyphal growth observed for plants infected with the wild-type strain, the $m k k A$ and $m p k A$ mutants had a proliferative pattern of growth. There was an increase in the number of hyphae in the intercellular spaces of the leaves and colonization of the large vascular bundles, phenotypes not seen in wild-type associations. The apparent increase in host "virulence" observed for the E. festucae CWI MAPK mutants and related symbiosis mutants is in contrast to a reduction in virulence observed for the same mutations in a number of phytopathogenic fungi (Hou et al. 2002; Igbaria et al. 2008; Jeon et al. 2008; Kojima et al. 2002; Mey et al. 2002; Xu et al. 1998). In some cases, the inability of these fungi to infect the host was due to a defect in appressorium peg formation, thereby preventing breach 
of the host cuticle (Igbaria et al. 2008; Jeon et al. 2008; Xu et al. 1998). But even when this step was bypassed by direct injection of hyphae into the plant, colonization of the host was still blocked (Jeon et al. 2008), a result that suggests that the CWI MAPK pathway is required for specific pathogen differentiation steps and invasive growth of the host. The pattern of proliferative growth observed for the $m k k A$ and $m p k A$ mutants appears to be a consequence of the inability of the lateral branches of hyphae, that grow between the junctions of the columns of plant cells that separate individual hyphae, to undergo cell-cell fusion. Instead of forming hyphal bridges through columns of plant cells that separate longitudinal hyphae, the lateral branches appear to grow past and around one another to form complex bundles of unfused hyphae. The failure of these mutants to form an interconnected symbiotic hyphal network within the leaf could lead to a breakdown in intrahyphal communication and nutrient transfer, possibly triggering a nutrient starvation response.

In addition to the fusion defect, TEM revealed major structural changes to the fungal cell wall; the outer cell-wall layer of some hyphae appears to be absent in both the $m k k A$ and $m p k A$ mutants. Consistent with this ultrastructural change was the unmasking of cell-wall chitin as detected by the increase in hyphal cell-wall fluorescence following staining of the leaves with Alexafluor 488 WGA. In leaves infected with the wild type, only the septa of the hyphae fluoresce; whereas, in leaves infected with the $m k k A$ and $m p k A$ mutants, large sections of hyphae fluoresce. This unmasking of $E$. festucae cell-wall chitin is likely to cause a pathogen-associated molecular pattern (PAMP)-triggered immunity (PTI) response in the host, which may account for the dramatic wholeplant and cellular responses observed in plants infected with $m k k A$ and $m p k A$ mutants. In the $M$. oryzae-rice pathogenic interaction, fungal cell-wall PAMPs are masked by $\alpha-1,3$ glucans, thereby enhancing the virulence of the pathogen (Fujikawa et al. 2009, 2012). However, the absence of a gene encoding $\alpha-1,3$-glucan synthase in the E. festucae genome does not support a role for $\alpha-1,3$-glucans in chitin masking. In the Cladosporium fulvum-tomato pathogenic interaction, the fungal small-secreted effector proteins Avr4 and Ecp6 have been shown to bind chitin, thereby enhancing the virulence of the pathogen (de Jonge et al. 2010; van den Burg et al. 2006; van Esse et al. 2007). Avr4 is proposed to bind to chitin in the fungal cell wall, thereby preventing hydrolysis of the cell wall by plant chitinases and release of chitin fragments that could trigger a host immune response (van den Burg et al. 2006; van Esse et al. 2007). Ecp6 is proposed to sequester chitin oligosaccharides released from the cell wall of invasive hyphae, thereby preventing PTI (de Jonge et al. 2010). In an RNAseq comparison of genes differentially expressed between the E. festucae wild type and $\Delta s a k A$, a number of genes encoding small-secreted proteins, including a chitinase, were identified; however, whether any of these fulfil similar roles to Avr4 and Ecp6 in the E. festucae-L. perenne symbiosis remains to be determined (Eaton et al. 2010).

In conclusion, we have demonstrated that the CWI MAPK pathway is a key signaling pathway for controlling the mutualistic symbiotic interaction between E. festucae and L. perenne. The similarities in both culture and plant interaction phenotypes of the $m k k A$ and $m p k A$ mutants with the noxA, noxR, proA, and so mutants would suggest that these genes are components of a conserved regulatory network controlling fungus-plant symbiosis. In other fungi, this same regulatory network is used for establishment of vegetative hyphal networks, sexual fruiting body development, and host colonization, underscoring its general importance for regulating multicellular developmental processes in fungi. Identifying the other components of this regula- tory network and the connections between them will be of considerable future interest.

\section{MATERIALS AND METHODS}

\section{Strains and growth conditions.}

Escherichia coli cultures were grown overnight in LuriaBertani (LB) broth or on LB agar, as previously described (Miller 1972).

Cultures of Epichloë festucae were grown on $2.4 \%$ PDA and $1.5 \%$ water agar under conditions previously described (Moon et al. 1999, 2000). To test for stress sensitivity, cultures were grown on PDA supplemented with $0.01 \%$ SDS, $3 \mathrm{mM}$ caffeine, nikkomycin at $50 \mu \mathrm{g} / \mathrm{ml}, 0.7 \mathrm{mM}$ sorbitol, $0.3 \mathrm{mM} \mathrm{NaCl}, 7 \mathrm{mM}$ $\mathrm{H}_{2} \mathrm{O}_{2}, 1 \mathrm{mM}$ diamide, and $40 \mathrm{mM}$ menadione. Sensitivity to Calcofluor white (Fluorescent Brighter 28; Sigma) at 10 and 25 $\mu \mathrm{g} / \mathrm{ml}$ and $50 \mathrm{mM}$ Congo red was tested on buffered PDA (50 $\mathrm{mM}$ HEPES, $\mathrm{pH}$ 6.5) to ensure that the test compounds remained soluble (Ram and Klis 2006). For temperature stress, strains were grown on PDA at $30^{\circ} \mathrm{C}$. A description of all biological material is provided in Supplementary Table S1.

\section{Plant growth and endophyte inoculation conditions.}

Endophyte-free seedlings of perennial ryegrass $(L$. perenne 'Samson') were inoculated with E. festucae by the method of Latch and Christensen (1985). Plants were grown in root trainers in an environmentally controlled growth room at $22^{\circ} \mathrm{C}$ with a photoperiod of $16 \mathrm{~h}$ of light (approximately $100 \mu \mathrm{E} / \mathrm{m}^{2} / \mathrm{s}$ ).

\section{DNA isolation, PCR, TAIL-PCR, and sequencing.}

Fungal genomic DNA was extracted from freeze-dried mycelium by the method of Byrd and associates (1990). Isolation of plasmid DNA was performed using a High Pure plasmid isolation kit (Roche) according to the manufacturer's instructions. Standard PCR and TAIL-PCR amplification was performed with Taq DNA polymerase (Roche). When proofreading activity was required, PCR was performed with the Expand High-Fidelity PCR system (Roche) or Phusion High-Fidelity DNA polymerase (NEB). The reaction mixture for Taq DNA polymerase or the Expand High-Fidelity PCR system $(50 \mu \mathrm{l})$ contained $1 \times$ Taq PCR Reaction buffer or $1 \times$ Expand High-Fidelity Buffer, 0.2 $\mu \mathrm{M}$ forward and reverse primers, $200 \mu \mathrm{M}$ dNTPs, $1 \mathrm{ng}$ of template DNA, and $1 \mathrm{U}$ of $\mathrm{Taq}$ polymerase or $1.75 \mathrm{U}$ of Expand High-Fidelity Enzyme Mix (Roche). The cycle conditions used were 1 cycle at $94^{\circ} \mathrm{C}$ for $2 \mathrm{~min} ; 36$ cycles at $94^{\circ} \mathrm{C}$ for $15 \mathrm{~s}, 50$ to $65^{\circ} \mathrm{C}$ for $30 \mathrm{~s}$, and 68 to $72^{\circ} \mathrm{C}$ for $1 \mathrm{~min} / \mathrm{kb}$; followed by a final extension cycle of $7 \mathrm{~min}$ at 68 to $72^{\circ} \mathrm{C}$. Reaction mixtures were stored at $4^{\circ} \mathrm{C}$ until analyzed. The reaction mixture for Phusion High-Fidelity DNA polymerase $(50 \mu \mathrm{l})$ contained $1 \times$ Phusion HF buffer, $0.5 \mu \mathrm{M}$ forward and reverse primers, $200 \mu \mathrm{M}$ dNTPs, $1 \mathrm{ng}$ of template DNA, and $1 \mathrm{U}$ of Phusion High-Fidelity DNA polymerase. The cycle conditions used were 1 cycle at $98^{\circ} \mathrm{C}$ for $30 \mathrm{~s} ; 10$ cycles at $98^{\circ} \mathrm{C}$ for $10 \mathrm{~s}, 50$ to $65^{\circ} \mathrm{C}$ for $30 \mathrm{~s}$, and $72^{\circ} \mathrm{C}$ for $30 \mathrm{~s} / \mathrm{kb} ; 20$ cycles at $98^{\circ} \mathrm{C}$ for $10 \mathrm{~s}$ and $72^{\circ} \mathrm{C}$ for $30 \mathrm{~s} / \mathrm{kb}$; followed by a final extension cycle of $5 \mathrm{~min}$ at $72^{\circ} \mathrm{C}$. TAIL-PCR was performed as previously described (Liu and Whittier 1995; Terauchi and Kahl 2000), with minor changes described by Giesbert and associates (2012). Lists of the primer sequences used for TAIL and standard PCR can be found in Supplementary Tables S2 and S3.

DNA fragments were sequenced using the dideoxynucleotide chain termination method with the Big-Dye Terminator Version 3.1 Ready Reaction Cycle Sequencing Kit (Applied BioSystems) and separated using an ABI3730 genetic analyzer (Applied BioSystems). Sequence data were assembled and analyzed using the MacVector sequence assembly software, version 12.0.5. 


\section{DNA hybridization.}

E. festucae genomic digests separated by agarose gel electrophoresis were transferred to positively charged nylon membranes (Roche) and fixed by UV light cross-linking in a Cex800 UV light cross-linker (Ultra-Lum) at $254 \mathrm{~nm}$ for $2 \mathrm{~min}$. DNA was labeled by random priming with Klenow DNA polymerase and $\left[\alpha-{ }^{32} \mathrm{P}\right]$-dCTP $(3,000 \mathrm{Ci} / \mathrm{mmol}$; Amersham Biosciences), using a High Prime DNA labeling kit (Roche), or by the incorporation of digoxigenin (DIG)-11-dUTP into DNA by PCR, using a PCR DIG probe synthesis kit (Roche). Hybridizations were performed according to the manufacturer's instructions and visualized by either autoradiography $\left({ }^{32} \mathrm{P}\right.$-labeled probes) or by nitroblue tetrazolium and 5 bromo4-chloro-3-indolyl phosphate color detection (DIG-labeled probes).

\section{Preparation of expression and deletion constructs.}

The PltmM-gusA knock-in vector pKM6 (PN1921) was generated by cloning a 2.6-kb XmaI fragment containing uidATtrpC from phFunGus into pCY39 (ltmM KO construct, PN1856) (Young et al. 2005).

The $m p k A$ and $m k k A$ replacement constructs were generated using yeast recombinational cloning (Colot et al. 2006). Phusion High-Fidelity DNA polymerase (NEB) was used to amplify the fragments. For generation of the $m p k A$ replacement construct, pCE64 (PN4155), a 968-bp PCR fragment 5' of $m p k A$, and a 1,315-bp PCR fragment $3^{\prime}$ of $m p k A$ were amplified. For generation of the $m k k A$ replacement construct, pCE63 (PN4154), a 1,515-bp PCR fragment 5' of $m k k A$, and a 1,432-bp PCR fragment $3^{\prime}$ of $m k k A$ were amplified. To facilitate yeast recombinational cloning, primers for amplification of the $m p k A$ and $m k k A 5^{\prime}$ flanking fragments contained overlap to the yeast vector pRS426 (YB165 and YB169) and to the $h p h$ hygromycin resistance cassette (YB166 and YB170), and primers for amplification of the $3^{\prime}$ flanking fragment contained overlap to the $h p h$ resistance cassette (YB167 and YB171) and to pRS426 (YB168 and YB172). The PtrpC-hph cassette was amplified with primers YB173 and YB174. Yeast cells were transformed with EcoRI/XhoI-linearized pRS426 together with PCR-amplified fragments of the PtrpC-hph cassette and $m p k A$ or $m k k A 5^{\prime}$ and $3^{\prime}$ flanking regions, as previously described (Gietz and Woods 2002). Transformants were selected on media lacking uracil, and plasmid DNA were isolated and transformed into $E$. coli.

The pusA complementation construct pYR29 was prepared by cloning the full-length pusA gene containing 905-bp $5^{\prime}$ and 595-bp 3' PCR amplified from E. festucae Fl1 genomic DNA with primers YB124 and YB125 into pCR4-TOPO (Invitrogen).

The $m k k A$ complementation constructs pYR31 and pYR33 were prepared by cloning the full-length $m k k A$ gene containing 998-bp 5' and 1,682-bp 3' of $m k k A$ amplified from E. festucae F11 genomic DNA with primers YB118 and YB119 into pAN8-1 (containing a ble cassette) and pII99 (containing the nptII cassette), respectively.

The $m p k A$ complementation construct pYR32 was prepared by cloning the full-length $m p k A$ gene containing $1-\mathrm{kb} 5^{\prime}$ and 446-bp 3' of $m p k A$ amplified from E. festucae Fl1 genomic DNA with primers 137 and 138 into pSF17.1, a pII99-based vector containing the nptII cassette (Tanaka et al. 2008).

\section{E. festucae transformation and screening for mutants.}

For A. tumefaciens T-DNA-mediated mutagenesis, A. tumefaciens EH105 (PN1828) was used to transform E. festucae strain KM2.49 (PN2599), as previously described (Tanaka et al. 2007, 2013).

E. festucae protoplasts were prepared as previously described (Young et al. 2005). Protoplasts were transformed with 3 to $5 \mu \mathrm{g}$ of linear PCR-amplified, restriction enzyme digested, or circular plasmid DNA using the method previously described (Itoh et al. 1994). Transformants were selected on regeneration medium (PD with $0.8 \mathrm{M}$ sucrose) containing either hygromycin $(150 \mu \mathrm{g} / \mathrm{ml})$, geneticin $(200 \mu \mathrm{g} / \mathrm{ml})$, zeocin $(250 \mu \mathrm{g} / \mathrm{ml})$, or nourseothricin $(250 \mu \mathrm{g} / \mathrm{ml})$ and nuclear purified by three rounds of subculturing on PD medium containing the same antibiotic selection.

To generate the PltmM-gusA knock-in, Fl1 protoplasts were transformed with a linear FspI/SapI pKM6 fragment and transformants were selected on medium containing hygromycin at $150 \mu \mathrm{g} / \mathrm{ml}$. Transformants were screened with primers lol134 and lol135 to distinguish the wild type $(1.7 \mathrm{~kb})$ from replacement sequences $(4.2 \mathrm{~kb})$.

For pusA complementation of the T-DNA mutant TM1066, protoplasts were co-transformed with pYR29 and pNR1 and transformants selected on medium containing nourseothricin $(250 \mu \mathrm{g} / \mathrm{ml})$. Reintroduction of the pusA gene was confirmed by PCR using primers YB163 and YB164.

For $m k k A$ complementation of the T-DNA mutant TM1066, protoplasts were co-transformed with pYR31 and pAN8-1 and transformants were selected on medium containing zeocin $(250 \mu \mathrm{g} / \mathrm{ml})$. Reintroduction of the $m k k A$ gene was confirmed by PCR using primers YB148 and YB149.

Putative $m k k A$ replacement mutants were screened by PCR using primers that flank the $h p h$ cassette (YB175 and YB176; $2.5 \mathrm{~kb}$ for wild-type sequence and $1.5 \mathrm{~kb}$ for replacement sequence) and the $5^{\prime}$ (YB181 and TC45; $2.2 \mathrm{~kb}$ ) and 3' (YB182 and TC44; $2 \mathrm{~kb}$ ) flanking regions of the replacement. Deletion of the $m k k A$ region was confirmed by PCR using primer YB185 and YB186 (457 bp in the wild type).

Putative $m p k A$ replacement mutants were screened by PCR using primers that flank the $h p h$ cassette (YB177 and YB178; $1.3 \mathrm{~kb}$ for the wild type and $1.5 \mathrm{~kb}$ for replacement sequence) and the 5' (YB179 and TC45; $1.6 \mathrm{~kb}$ ) and 3' (YB180 and TC44; $2 \mathrm{~kb}$ ) flanking regions of the replacement. Deletion of the $m p k A$ region was confirmed by PCR using primer YB183 and YB184 (329 bp in the wild type).

For complementation of knock-out strains, protoplasts of $\Delta m k k A 4-2$ and $\Delta m p k A 10.8$ were transformed with pYR33 and pYR32, respectively, and transformants selected on medium containing geneticin $(200 \mu \mathrm{g} / \mathrm{ml})$. Reintroduction of the $m k k A$ or $m p k A$ gene was confirmed by PCR using primers YB148 and YB149 $(m k k A)$ and YB183 and YB184 (mpkA), respectively.

mRFP and eGFP transformants of the E. festucae wild type, $\triangle m k k A$, and $\triangle m p k A$ were generated by transforming protoplasts of each of these strains with pCA56 (pToxA-mRFP) and pCT74 (pToxA-eGFP), respectively (Andrie et al. 2005).

\section{Western blot analysis.}

E. festucae cultures were grown for 5 days in $50 \mathrm{ml}$ of $\mathrm{PD}$ at $22^{\circ} \mathrm{C}$ and $180 \mathrm{rpm}$. After harvesting, the mycelium was washed three times with sterile Milli-Q water, frozen in liquid nitrogen, and freeze dried overnight. The mycelium was ground to a fine powder under liquid nitrogen. For protein extraction, $50 \mathrm{mg}$ of the mycelium powder was homogenized in $1 \mathrm{ml}$ of lysis buffer (50 mM Tris-HCl [pH 8], $100 \mathrm{mM} \mathrm{NaCl}, 10 \mathrm{mM}$ EDTA, IGEPAL CA-630 [Sigma-Aldrich] at $1 \mu \mathrm{l} / \mathrm{ml}, 0.5 \mathrm{mM}$ phenylmethylsulfonyl fluoride, $2 \mathrm{mM}$ dithiothreitol, and phosphatase inhibitor [Sigma-P5726] at $10 \mu \mathrm{l} / \mathrm{ml}$ ) and centrifuged at $14,000 \mathrm{rpm}$ for $15 \mathrm{~min}$ at $4^{\circ} \mathrm{C}$. The supernatant was retained and centrifuged a second time as described above. Protein concentrations were measured using the Bio-Rad Protein Assay Dye Reagent Concentrate (Bio-Rad catalog number 500-0006) following the manufacturer's instructions. Samples of protein $(50 \mu \mathrm{g}$ each) were separated on a $10 \%(\mathrm{wt} / \mathrm{vol})$ SDS polyacrylamide gel and transferred to polyvinylidene diflouride mem- 
branes (Roche). The phosphorylation of MpkA and MpkB was examined using anti-phospho-p44/42 MAPK (Erk1/2) antibody (number 9102; Cell Signalling Technology). To check the amount of protein loaded for each sample, the membrane was reprobed with $12 \mathrm{G} 10$ anti- $\alpha$-tubulin (DSHB). Primary antibodies were detected using HPR-conjugated secondary antibodies and ECL Prime Western Blotting Detection Reagent (GE Healthcare Amersham).

\section{Microscopy.}

Cultures to be analyzed by microscopy were inoculated at the edge of a thin layer of PD agarose $(1.5 \%)$ or water agarose $(1.5 \%)$ layered on top of a glass microscopy slide embedded in a layer of PDA $(1.5 \%)$ or water agar $(1.5 \%)$ and grown for 5 days. Images of Calcofluor white (Fluorescent Brighter 28; Sigma)-stained hyphae and eGFP and mRFP1 fluorescence in E. festucae hyphae were captured by confocal laser-scanning microscopy using a Leica SP5 DM6000B confocal microscope (488 $\mathrm{nm}$ argon laser, $\times 40$ oil immersion objective, numerical aperture $=1.3$ ) (Leica Microsystems) or an Olympus IX71 inverted fluorescence microscope. For statistical analyses of hyphal fusion, 10 fusion sites were analyzed starting from the tip of a hypha and counting fusions along the two partner hyphae as well as the number of septa of each hypha. Fusion frequency was calculated as the number of fusions per septum from four independent colonies. For analyses of conidiation, four PDA plates with four colonies of each strain were grown at $22^{\circ} \mathrm{C}$ for 6 days. Spores were harvested by scrubbing the colonies with $3 \mathrm{ml}$ of sterile water. The suspension was filtered through glass wool filtered tips and 100, 200, and $300 \mu \mathrm{l}$ was spread on PDA $(1.5 \%)$ or water agar $(1.5 \%)$ plates. Spore germination and colony formation were monitored after 4 to 5 days. MpkA-gfp localization and 4',6-diamidino-2-phenylindole staining of arthroconidia was performed as previously described (Cartwright et al. 2014).

Growth and morphology of E. festucae hyphae in planta was determined by staining leaves with aniline blue diammonium salt (Sigma) and AlexaFluor-488 WGA (Molecular Probes) as follows. Tillers of perennial ryegrass infected with $E$. festucae were soaked in $95 \%(\mathrm{vol} / \mathrm{vol})$ ethanol overnight at $4{ }^{\circ} \mathrm{C}$, then treated with $10 \%$ potassium hydroxide for $3 \mathrm{~h}$. The tissue was washed three times with phosphate-buffered saline (PBS) $(\mathrm{pH}$ $7.4)$ and incubated in staining solution $(0.02 \%$ aniline blue, AF488-WGA at $10 \mathrm{ng} / \mathrm{ml}$, and $0.02 \%$ Tween 20 in PBS [pH 7.4] for $5 \mathrm{~min}$, followed by $30 \mathrm{~min}$ of vacuum infiltration). Images of E. festucae hyphae and septa in planta were captured by confocal laser-scanning microscopy using a Leica SP5 DM6000B confocal microscope (488 nm argon and $561 \mathrm{~nm}$ DPSS laser, $\times 40$ oil immersion objective, NA $=1.3$ ) (Leica Microsystems).

For TEM, pseudostem sections were fixed in 3\% glutaraldehyde and $2 \%$ formaldehyde in $0.1 \mathrm{M}$ phosphate buffer, $\mathrm{pH} 7.2$, for $1 \mathrm{~h}$, as described by Spiers and Hopcroft (1993). A Philips CM10 TEM was used to examine the fixed samples and the images were acquired using an SIS Morada digital camera.

\section{Bioinformatic analysis and accession numbers.}

E. festucae genes were identified by tBLASTn analysis of the E. festucae Fl1 (E894) genome with protein sequences obtained from either the National Center for Biotechnology Information GenBank database or the Broad Institute. The $E$. festucae genome sequence data (Schardl et al. 2013) is available from the University of Kentucky. Identity and similarity scores were calculated after ClustalW pairwise alignments of sequences, using MacVector version 12.0.5. Multiple sequence alignments were edited using Jalview. For protein functional analysis, InterProScan 4 EMBL/EBI was used.
The pusA, $m k k A$, and $m p k A$ gene sequences of E. festucae strain Fl1 (894) are available in the GenBank database under accession numbers KJ605834 (pusA), KJ605833 (mkkA), and KJ605832 (mpkA), respectively.

\section{ACKNOWLEDGMENTS}

This research was supported by grants from the Royal Society of New Zealand Marsden Fund, contract MAU0701; the Tertiary Education Commission to the Bio-Protection Research Centre, contract PR58668; and Massey University. We thank D. Hopcroft, J. Chen, J. Taylor, and M. Savoian (Manawatu Microscopy and Imaging Centre, Massey University), R. Wrenn, and A. Ram for technical assistance; T. Chujo for statistical advice; L. Ciuffetti (Oregon State University) for provision of plasmids pCT74 and pCA56; and C. Schardl for provision of Clavicipitaceae genome sequences, made available through funding from the U.S. National Science Foundation (grant number EF-0523661), the U.S. Department of Agriculture National Research initiative (grant number 2005-35319-16141), and the National Institutes of Health (grant number 2 P20 RR-16481). Y. Becker, C. J. Eaton, and B. Scott designed the research; Y. Becker, C. J. Eaton, E. Brasell, K. J. May, M. Becker, B. Hassing, G. M. Cartwright, and L. Reinhold performed the research; Y. Becker, C. J. Eaton, E. Brasell, K. J. May, M. Becker, G. M. Cartwright, and B. Scott analyzed the data; and Y. Becker and B. Scott wrote the paper.

\section{LITERATURE CITED}

Aldabbous, M. S., Roca, M. G., Stout, A., Huang, I. C., Read, N. D., and Free, S. J. 2010. The ham-5, rcm-1 and rco-1 genes regulate hyphal fusion in Neurospora crassa. Microbiology 156:2621-2629.

Anderson, J. G., and Smith, J. E. 1971. The production of conidiophores and conidia by newly germinated conidia of Aspergillus niger (microcycle conidiation). J. Gen. Microbiol. 69:185-197.

Andrie, R. M., Martinez, J. P., and Ciuffetti, L. M. 2005. Development of ToxA and ToxB promoter-driven fluorescent protein expression vectors for use in filamentous ascomycetes. Mycologia 97:1152-1161.

Bacon, C. W., and Hinton, D. M. 1991. Microcyclic conidiation cycles in Epichloë typhina. Mycologia 83:743-751.

Bowman, S. M., Piwowar, A., Al Dabbous, M., Vierula, J., and Free, S. J. 2006. Mutational analysis of the glycosylphosphatidylinositol (GPI) anchor pathway demonstrates that GPI-anchored proteins are required for cell wall biogenesis and normal hyphal growth in Neurospora crassa. Eukaryot. Cell 5:587-600.

Buller, A. H. R. 1933. Researches on Fungi. Longman, London.

Byrd, A. D., Schardl, C. L., Songlin, P. J., Mogen, K. L., and Siegel, M. R. 1990. The $\beta$-tubulin gene of Epichloë typhina from perennial ryegrass (Lolium perenne). Curr. Genet. 18:347-354.

Calonge, F. D. 1968. Origin and development of intrahyphal hyphae in Sclerotinia fructigena. Mycologia 60:932-942.

Cartwright, G. M., Tanaka, A., Eaton, C. J., and Scott, B. 2014. Formation of arthroconidia during regeneration and selection of transformed Epichloë festucae protoplasts. Fungal Biol. 118:462-471.

Chan, C., and Stephen, R. C. 1967. Intrahyphal hyphae in the genus Linderina. Can. J. Bot. 45:1995-1998.

Chan, C. M., and Huang, R. H. 2009. Enzymatic characterization and mutational studies of TruD-The fifth family of pseudouridine synthases. Arch. Biochem. Biophys. 489:15-19.

Charlton, N. D., Shoji, J. Y., Ghimire, S. R., Nakashima, J., and Craven, K. D. 2012. Deletion of the fungal gene soft disrupts mutualistic symbiosis between the grass endophyte Epichlö festucae and the host plant. Eukaryot. Cell 11:1463-1471.

Choi, J., Park, J., Jeon, J., Chi, M. H., Goh, J., Yoo, S. Y., Park, J., Jung, K., Kim, H., Park, S. Y., Rho, H. S., Kim, S., Kim, B. R., Han, S. S., Kang, S., and Lee, Y. H. 2007. Genome-wide analysis of T-DNA integration into the chromosomes of Magnaporthe oryzae. Mol. Microbiol. 66:371-382.

Christensen, M. J., Bennett, R. J., and Schmid, J. 2002. Growth of Epichloël Neotyphodium and p-endophytes in leaves of Lolium and Festuca grasses. Mycol. Res. 106:93-106.

Christensen, M. J., Bennett, R. J., Ansari, H. A., Koga, H., Johnson, R. D., Bryan, G. T., Simpson, W. R., Koolaard, J. P., Nickless, E. M., and Voisey, C. R. 2008. Epichlö endophytes grow by intercalary hyphal extension in elongating grass leaves. Fungal Genet. Biol. 45:84-93.

Chung, K.-R., and Schardl, C. L. 1997. Sexual cycle and horizontal transmission of the grass symbiont, Epichlö typina. Mycol. Res. 101:295-301.

Colot, H. V., Park, G., Turner, G. E., Ringelberg, C., Crew, C. M., Litvinkova, L., Weiss, R. L., Borkovich, K. A., and Dunlap, J. C. 2006. 
A high-throughput gene knockout procedure for Neurospora reveals functions for multiple transcription factors. Proc. Natl. Acad. Sci. U.S.A. 103:10352-10357.

de Jonge, R., van Esse, H. P., Kombrink, A., Shinya, T., Desaki, Y., Bours, R., van der Krol, S., Shibuya, N., Joosten, M. H., and Thomma, B. P. 2010. Conserved fungal LysM effector Ecp6 prevents chitin-triggered immunity in plants. Science 329:953-935.

Eaton, C., Mitic, M., and Scott, B. 2011. Signalling in the Epichlöe festucae-perennial ryegrass mutualistic symbiotic interaction. Pages 143-181 in: Signaling and Communication in Plant Symbiosis. S. Perotto and F. Baluska, eds. Springer-Verlag, Heidelberg, Germany.

Eaton, C. J., Cox, M. P., Ambrose, B., Becker, M., Hesse, U., Schardl, C. L., and Scott, B. 2010. Disruption of signaling in a fungal-grass symbiosis leads to pathogenesis. Plant Physiol. 153:1780-1794.

Fleissner, A., Leeder, A. C., Roca, M. G., Read, N. D., and Glass, N. L. 2009. Oscillatory recruitment of signaling proteins to cell tips promotes coordinated behavior during cell fusion. Proc. Natl. Acad. Sci. U.S.A. 106:19387-19392.

Fricker, M. D., Boddy, L., and Bebber, D. 2007. Network organisation of filamentous fungi. Pages 309-330 in: Biology of the Fungal Cell. R. J. Howard and N. A. R. Gow, eds. Springer-Verlag, Berlin.

Fu, C., Iyer, P., Herkal, A., Abdullah, J., Stout, A., and Free, S. J. 2011. Identification and characterization of genes required for cell-to-cell fusion in Neurospora crassa. Eukaryot. Cell 10:1100-1109.

Fujikawa, T., Kuga, Y., Yano, S., Yoshimi, A., Tachiki, T., Abe, K., and Nishimura, M. 2009. Dynamics of cell wall components of Magnaporthe grisea during infectious structure development. Mol. Microbiol. 73:553-570.

Fujikawa, T., Sakaguchi, A., Nishizawa, Y., Kouzai, Y., Minami, E., Yano, S., Koga, H., Meshi, T., and Nishimura, M. 2012. Surface alpha-1,3glucan facilitates fungal stealth infection by interfering with innate immunity in plants. PLoS Pathog. 8:e1002882.

Giesbert, S., Schumacher, J., Kupas, V., Espino, J., Segmüller, N., HaeuserHahn, I., Schreier, P. H., and Tudzynski, P. 2012. Identification of pathogenesis-associated genes by T-DNA-mediated insertional mutagenesis in Botrytis cinerea: A type 2A phosphoprotein phosphatase and an SPT3 transcription factor have significant impact on virulence. Mol. Plant-Microbe Interact. 25:481-495.

Gietz, R. D., and Woods, R. A. 2002. Transformation of yeast by lithium acetate/single-stranded carrier DNA/polyethylene glycol method. Meth. Enzymol. 350:87-96.

Hanlin, R. T. 1994. Microcycle conidiation-A review. Mycoscience 35:113-123.

Hickey, P. C., Jacobson, D., Read, N. D., and Glass, N. L. 2002. Live-cell imaging of vegetative hyphal fusion in Neurospora crassa. Fungal Genet. Biol. 37:109-119.

Horiuchi, H., Fujiwara, M., Yamashita, S., Ohta, A., and Takagi, M. 1999. Proliferation of intrahyphal hyphae caused by disruption of $\operatorname{csmA}$, which encodes a class V chitin synthase with a myosin motor-like domain in Aspergillus nidulans. J. Bacteriol. 181:3721-3729.

Hou, Z., Xue, C., Peng, Y., Katan, T., Kistler, H. C., and Xu, J. R. 2002. A mitogen-activated protein kinase gene $(M G V 1)$ in Fusarium graminearum is required for female fertility, heterokaryon formation, and plant infection. Mol. Plant-Microbe Interact. 15:1119-1127.

Igbaria, A., Lev, S., Rose, M. S., Lee, B. N., Hadar, R., Degani, O., and Horwitz, B. A. 2008. Distinct and combined roles of the MAP kinases of Cochliobolus heterostrophus in virulence and stress responses. Mol. Plant-Microbe Interact. 21:769-780.

Irie, K., Takase, M., Lee, K.S., Levin, D. E., Araki, H., Matsumoto, K., and Oshima, Y. 1993. MKK1 and MKK2, which encode Saccharomyces cerevisiae mitogen-activated protein kinase-kinase homologs, function in the pathway mediated by protein kinase C. Mol. Cell. Biol. 13:30763083.

Itoh, Y., Johnson, R., and Scott, B. 1994. Integrative transformation of the mycotoxin-producing fungus, Penicillium paxilli. Curr. Genet. 25:508513.

Jeon, J., Park, S. Y., Chi, M. H., Choi, J., Park, J., Rho, H. S., Kim, S., Goh, J., Yoo, S., Park, J. Y., Yi, M., Yang, S., Kwon, M. J., Han, S. S., Kim, B. R., Khang, C. H., Park, B., Lim, S. E., Jung, K., Kong, S., Karunakaran, M., Oh, H. S., Kim, H., Kang, S., Choi, W. B., and Lee, Y. H. 2007. Genome-wide functional analysis of pathogenicity genes in the rice blast fungus. Nat. Genet. 39:561-565.

Jeon, J., Goh, J., Yoo, S., Chi, M. H., Choi, J., Rho, H. S., Park, J., Han, S. S., Kim, B. R., Park, S. Y., Kim, S., and Lee, Y. H. 2008. A putative MAP kinase kinase kinase, $M C K 1$, is required for cell wall integrity and pathogenicity of the rice blast fungus, Magnaporthe oryzae. Mol. Plant-Microbe Interact. 21:525-534.

Kayano, Y., Tanaka, A., Akano, F., Scott, B., and Takemoto, D. 2013. Differential roles of NADPH oxidases and associated regulators in polarized growth, conidiation and hyphal fusion in the symbiotic fungus
Epichlö̈ festucae. Fungal Genet. Biol. 56:87-97.

Kicka, S., and Silar, P. 2004. PaASK1, a mitogen-activated protein kinase kinase kinase that controls cell degeneration and cell differentiation in Podospora anserina. Genetics 166:1241-1252.

Kojima, K., Kikuchi, T., Takano, Y., Oshiro, E., and Okuno, T. 2002. The mitogen-activated protein kinase gene $M A F 1$ is essential for the early differentiation phase of appressorium formation in Colletotrichum lagenarium. Mol. Plant-Microbe Interact. 15:1268-1276.

Lai, J., Koh, C. H., Tjota, M., Pieuchot, L., Raman, V., Chandrababu, K. B., Yang, D., Wong, L., and Jedd, G. 2012. Intrinsically disordered proteins aggregate at fungal cell-to-cell channels and regulate intercellular connectivity. Proc. Natl. Acad. Sci. U.S.A. 109:15781-15786.

Latch, G. C. M., and Christensen, M. J. 1985. Artificial infection of grasses with endophytes. Ann. Appl. Biol. 107:17-24.

Leeder, A. C., Jonkers, W., Li, J., and Glass, N. L. 2013. Early colony establishment in Neurospora crassa requires a MAP kinase regulatory network. Genetics 195:883-898.

Leuchtmann, A., Schardl, C. L., and Siegel, M. R. 1994. Sexual compatibility and taxonomy of a new species of Epichlö̈ symbiotic with fine fescue grasses. Mycologia 86:802-812.

Levin, D. E. 2005. Cell wall integrity signaling in Saccharomyces cerevisiae. Microbiol. Mol. Biol. Rev. 69:262-291.

Lichius, A., Lord, K. M., Jeffree, C. E., Oborny, R., Boonyarungsrit, P., and Read, N. D. 2012. Importance of MAP kinases during protoperithecial morphogenesis in Neurospora crassa. PLoS One 7:e42565.

Liu, F., Ng, S. K., Lu, Y., Low, W., Lai, J., and Jedd, G. 2008. Making two organelles from one: Woronin body biogenesis by peroxisomal protein sorting. J. Cell Biol. 180:325-339.

Liu, Y.-G., and Whittier, R. F. 1995. Thermal asymmetric interlaced PCR: Automatable amplification and sequencing of insert end fragments from P1 and YAC clones for chromosome walking. Genomics 25:674-681.

Maddi, A., Dettman, A., Fu, C., Seiler, S., and Free, S. J. 2012. WSC-1 and HAM-7 are MAK-1 MAP kinase pathway sensors required for cell wall integrity and hyphal fusion in Neurospora crassa. PLoS One 7:e42374.

Maerz, S., Ziv, C., Vogt, N., Helmstaedt, K., Cohen, N., Gorovits, R., Yarden, O., and Seiler, S. 2008. The nuclear Dbf2-related kinase COT1 and the mitogen-activated protein kinases MAK1 and MAK2 genetically interact to regulate filamentous growth, hyphal fusion and sexual development in Neurospora crassa. Genetics 179:1313-1325.

Masloff, S., Pöggeler, S., and Kück, U. 1999. The pro1(+) gene from Sordaria macrospora encodes a C6 zinc finger transcription factor required for fruiting body development. Genetics 152:191-199.

Masloff, S., Jacobsen, S., Pöggeler, S., and Kück, U. 2002. Functional analysis of the $\mathrm{C} 6$ zinc finger gene prol involved in fungal sexual development. Fungal Genet. Biol. 36:107-116.

Mey, G., Held, K., Scheffer, J., Tenberge, K. B., and Tudzynski, P. 2002. CPMK2, an SLT2-homologous mitogen-activated protein (MAP) kinase, is essential for pathogenesis of Claviceps purpurea on rye: Evidence for a second conserved pathogenesis-related MAP kinase cascade in phytopathogenic fungi. Mol. Microbiol. 46:305-318.

Miller, J. H. 1972. Experiments in Molecular Genetics. Cold Spring Harbor Laboratory Press, Cold Spring Harbor, NY, U.S.A.

Moon, C. D., Tapper, B. A., and Scott, B. 1999. Identification of Epichlö̈ endophytes in planta by a microsatellite-based PCR fingerprinting assay with automated analysis. Appl. Environ. Microbiol. 65:1268-1279.

Moon, C. D., Scott, B., Schardl, C. L., and Christensen, M. J. 2000. The evolutionary origins of Epichlö̈ endophytes from annual ryegrasses. Mycologia 92:1103-1118.

Park, G., Pan, S., and Borkovich, K. A. 2008. Mitogen-activated protein kinase cascade required for regulation of development and secondary metabolism in Neurospora crassa. Eukaryot. Cell 7:2113-2122.

Pazantova, S. R., Rehazek, Z., and Porkorny, J. 1978. Microcycle sporulation in Claviceps purpurea. Folia Microbiol. 23:370-378.

Ram, A. F., and Klis, F. M. 2006. Identification of fungal cell wall mutants using susceptibility assays based on Calcofluor white and Congo red. Nat. Protocols 1:2253-2256.

Ramamurthy, V., Swann, S. L., Paulson, J. L., Spedaliere, C. J., and Mueller, E. G. 1999. Critical aspartic acid residues in pseudouridine synthases. J. Biol. Chem. 274:22225-22230.

Read, N. D., Lichius, A., Shoji, J. Y., and Goryachev, A. B. 2009. Self-signalling and self-fusion in filamentous fungi. Curr. Opin. Microbiol. 12:608-615.

Read, N. D., Fleissner, A., Roca, G. M., and Glass, N. L. 2010. Hyphal fusion. Pages 260-273 in: Cellular and Molecular Biology of Filamentous Fungi. K. A. Borkovich and D. J. Ebbole, eds. American Society for Microbiology, Washington, DC.

Read, N. D., Goryachev, A. B., and Lichius, A. 2012. The mechanistic basis of self-fusion between conidial anastomosis tubes during fungal colony initiation. Fungal Biol. Rev. 26:1-11. 
Rispail, N., Soanes, D. M., Ant, C., Czajkowski, R., Grunler, A., Huguet, R., Perez-Nadales, E., Poli, A., Sartorel, E., Valiante, V., Yang, M., Beffa, R., Brakhage, A. A., Gow, N. A., Kahmann, R., Lebrun, M. H., Lenasi, H., Perez-Martin, J., Talbot, N. J., Wendland, J., and Di Pietro, A. 2009. Comparative genomics of MAP kinase and calcium-calcineurin signalling components in plant and human pathogenic fungi. Fungal Genet. Biol. 46:287-298.

Roca, G. M., Read, N. D., and Wheals, A. E. 2005a. Conidial anastomosis tubes in filamentous fungi. FEMS (Fed. Eur. Microbiol. Soc.) Microbiol. Lett. 249:191-198.

Roca, M. G., Arlt, J., Jeffree, C. E., and Read, N. D. 2005b. Cell biology of conidial anastomosis tubes in Neurospora crassa. Eukaryot. Cell 4:911-919.

Ruiz-Roldán, M. C., Kohli, M., Roncero, M. I., Philippsen, P., Di Pietro, A., and Espeso, E. A. 2010. Nuclear dynamics during germination, conidiation, and hyphal fusion of Fusarium oxysporum. Eukaryot. Cell 9:1216-1224

Schardl, C. L. 2001. Epichloë festucae and related mutualistic symbionts of grasses. Fungal Genet. Biol. 33:69-82.

Schardl, C. L., Young, C. A., Hesse, U., Amyotte, S. G., Andreeva, K., Calie, P. J., Fleetwood, D. J., Haws, D. C., Moore, N., Oeser, B., Panaccione, D. G., Schweri, K. K., Voisey, C. R., Farman, M. L., Jaromczyk, J. W., Roe, B. A., O'Sullivan, D. M., Scott, B., Tudzynski, P., An, Z.-Q., Arnaoudova, E. G., Bullock, C. T., Charlton, N. D., Chen, L., Cox, M., Dinkins, R. D., Florea, S., Glenn, A. E., Gordon, A., Güldener, U., Harris, D. R., Hollin, W., Jaromczyk, J., Johnson, R. D., Khan, A. K., Leistner, E., Leuchtmann, A., Li, C., Liu, J.-G., Liu, J., Liu, M., Mace, W., Machado, C., Nagabhyru, P., Pan, J., Schmid, J., Sugawara, K., Steiner, U., Takach, J. E., Tanaka, E., Webb, J. S., Wilson, E. V., Wiseman, J. L., Yoshida, R., and Zheng, Z. 2013. Plant-symbiotic fungi as chemical engineers: Multi-genome analysis of the Clavicipitaceae reveals dynamics of alkaloid loci. PLoS Genet. 9:e1003323.

Scott, B., Becker, Y., Becker, M., and Cartwright, G. 2012. Morphogenesis, growth and development of the grass symbiont Epichloe festucae. Pages 243-264 in: Morphogenesis and Pathogenicity in Fungi. J. P. Martin and A. Di Pietro, eds. Springer-Verlag, Heidelberg, Germany.

Simonin, A., Palma-Guerrero, J., Fricker, M., and Glass, N. L. 2010. Physiological significance of network organization in fungi. Eukaryot. Cell 11:1345-1352.

Smith, J. E., Anderson, J. G., Kristiansen, B., Alrawi, A., and Yahya, A. G. 1981. Microcycle conidiation. Pages 627-650 in: The Fungal Spore: Morphogenetic Controls. G. Turian and H. R. Hohl, eds. Academic Press, New York.

Spiers, A. G., and Hopcroft, D. H. 1993. Black canker and leaf spot of Salix in New Zealand caused by Glomerella miyabeana (Colletotrichum gloeosporioides). Eur. J. For. Pathol. 23:92-102.

Takemoto, D., Tanaka, A., and Scott, B. 2006. A p67 ${ }^{\text {Phox }}$-like regulator is recruited to control hyphal branching in a fungal-grass mutualistic symbiosis. Plant Cell 18:2807-2821.

Takemoto, D., Kamakura, S., Saikia, S., Becker, Y., Wrenn, R., Tanaka, A., Sumimoto, H., and Scott, B. 2011. Polarity proteins Bem1 and Cdc24 are components of the filamentous fungal NADPH oxidase complex. Proc. Natl. Acad. Sci. U.S.A. 108:2861-2866.

Tan, Y. Y., Spiering, M. J., Scott, V., Lane, G. A., Christensen, M. J., and Schmid, J. 2001. In planta regulation of extension of an endophytic fungus and maintenance of high metabolic rates in its mycelium in the absence of apical extension. Appl. Environ. Microbiol. 67:5377-5383.

Tanaka, A., Christensen, M. J., Takemoto, D., Park, P., and Scott, B. 2006. Reactive oxygen species play a role in regulating a fungus-perennial ryegrass mutualistic association. Plant Cell 18:1052-1066.
Tanaka, A., Wrenn, R. E., Takemoto, D., and Scott, B. 2007. Agrobacterium tumefaciens T-DNA mediated transformation of Epichloë festucae. Pages 469-472 in: Proc. 6th Int. Symp. Fungal Endophytes of Grasses. Grassland Research and Practice series No. 13. A. J. Popay and E. R. Thon, eds. New Zealand Grassland Association, Christchurch, New Zealand.

Tanaka, A., Takemoto, D., Hyon, G. S., Park, P., and Scott, B. 2008. NoxA activation by the small GTPase RacA is required to maintain a mutualistic symbiotic association between Epichloë festucae and perennial ryegrass. Mol. Microbiol. 68:1165-1178.

Tanaka, A., Cartwright, G. M., Saikia, S., Kayano, Y., Takemoto, D., Kato, M., Tsuge, T., and Scott, B. 2013. ProA, a transcriptional regulator of fungal fruiting body development, regulates leaf hyphal network development in the Epichloë festucae-Lolium perenne symbiosis. Mol. Microbiol. 90:551-568.

Terauchi, R., and Kahl, G. 2000. Rapid isolation of promoter sequences by TAIL-PCR: The 5'-flanking regions of $P a l$ and $P g i$ genes from yams (Dioscorea). Mol. Gen. Genet. 263:554-560.

Valiante, V., Jain, R., Heinekamp, T., and Brakhage, A. A. 2009. The MpkA MAP kinase module regulates cell wall integrity signaling and pyomelanin formation in Aspergillus fumigatus. Fungal Genet. Biol. 46:909-918.

van den Burg, H. A., Harrison, S. J., Joosten, M. H., Vervoort, J., and de Wit, P. J. 2006. Cladosporium fulvum Avr4 protects fungal cell walls against hydrolysis by plant chitinases accumulating during infection. Mol. Plant-Microbe Interact 19:1420-1430.

van Esse, H. P., Bolton, M. D., Stergiopoulos, I., de Wit, P. J., and Thomma, B. P. 2007. The chitin-binding Cladosporium fulvum effector protein Avr4 is a virulence factor. Mol. Plant-Microbe Interact. 20:1092-1101.

Vienken, K., and Fischer, R. 2006. The $\mathrm{Zn}(\mathrm{II})_{2} \mathrm{Cys}_{6}$ putative transcription factor NosA controls fruiting body formation in Aspergillus nidulans. Mol. Microbiol. 61:544-554.

Xu, J. R., Staiger, C. J., and Hamer, J. E. 1998. Inactivation of the mitogenactivated protein kinase Mps1 from the rice blast fungus prevents penetration of host cells but allows activation of plant defense responses. Proc. Natl. Acad. Sci. U.S.A. 95:12713-12718.

Young, C. A., Bryant, M. K., Christensen, M. J., Tapper, B. A., Bryan, G. T., and Scott, B. 2005. Molecular cloning and genetic analysis of a symbiosis-expressed gene cluster for lolitrem biosynthesis from a mutualistic endophyte of perennial ryegrass. Mol. Gen. Genomics 274:13 29 .

Young, C. A., Felitti, S., Shields, K., Spangenberg, G., Johnson, R. D., Bryan, G. T., Saikia, S., and Scott, B. 2006. A complex gene cluster for indole-diterpene biosynthesis in the grass endophyte Neotyphodium lolii. Fungal Genet. Biol. 43:679-693.

Yun, Y., Liu, Z., Zhang, J., Shim, W. B., Chen, Y., and Ma, Z. 2013. The MAPKK FgMkk1 of Fusarium graminearum regulates vegetative differentiation, multiple stress response, and virulence via the cell wall integrity and high-osmolarity glycerol signaling pathways. Environ. Microbiol. 16:2023-2037.

\section{AUTHOR-RECOMMENDED INTERNET RESOURCES}

Broad Institute: www.broad.mit.edu

E. festucae genome sequence data: csbio-1.csr.uky.edu/ef894-2011

GenBank: www.ncbi.nlm.nih.gov/genbank/index.html

InterProScan 4 EMBL/EBI: www.ebi.ac.uk/Tools/pfa/iprscan

Jalview: www.jalview.org

National Center for Biotechnology Information: www.ncbi.nlm.nih.gov 